\title{
Numerical Investigation of Tension Reinforcement Lap Length of Eurocode 2 Using a Four-Point Beam Loading System
}

\author{
Blessing Oluwaseun Adeleke ${ }^{a} \odot$ \\ Samuel Jonah Abbey ${ }^{\text {** }}$ \\ Adegoke Omotayo Olubanwoc (i) \\ a Department of Engineering, Faculty of Engineering, Technology and Science, University of South Wales, United Kingdom. E-mail: \\ blessing.adeleke@southwales.ac.uk \\ ${ }^{b}$ Department of Geography and Environmental Management, Faculty of Engineering and Technology, University of the West of England, \\ United Kingdom. E-mail: samuel.abbey@uwe.ac.uk \\ c School of Energy, Construction and Environment, Faculty of Engineering, Environment and Computing, Coventry University, United \\ Kingdom. E-mail: aa7878@coventry.ac.uk \\ *Corresponding author
}

http://dx.doi.org/10.1590/1679-78255532

\begin{abstract}
This report presents a computational research on Eurocode 2 (EC2) tension lap lengths (lo) design in a normally reinforced concrete beam, using ANSYS Workbench simulation software program by simulating a laboratory 4-point beam loading test system under static loading(discrete model approach). A typical 4-point laboratory setup loading system was modelled using an innovative and sustainable Finite Element Analysis (FEA) approach. In order to investigate the EC2 tension lap lengths $\left(I_{0}\right)$ design recommendation, a total of 100 analysis cases of lap lengths were considered for different reinforcement bar diameters of $10 \mathrm{~mm}, 12 \mathrm{~mm}$, $16 \mathrm{~mm}, 20 \mathrm{~mm}$ and $25 \mathrm{~mm}$. The study has considered beam failure types, effects of failure load on the various lap length reduction cases and effects of steel reinforcement bar size changes on the design lap lengths. The analysis of results revealed that the yield strength of steel $\left(f_{y k}\right)$, diameter of tension reinforcement bar, $\left(d_{b}\right)$, tensile strength of concrete $\left(f_{c t d}\right)$ and concrete cover $\left(c_{d}\right)$ are the main parameters for a tension lap length design according to EC2. While a linear relationship exists between tension steel reinforcement bar sizes $\left(d_{b}\right)$ and the obtained lap lengths $\left(\mathrm{I}_{\mathrm{o}}\right)$. The study reveals a potential use of $15 \%$ and $20 \%$ reduction in lap length $\left(\mathrm{I}_{0}\right)$ for tension steel reinforcement bar sizes of $10 \mathrm{~mm}, 16 \mathrm{~mm}$ and $12 \mathrm{~mm}$ and $20 \mathrm{~mm}$ in comparison with the recommended design lap length of EC2. It was concluded that EC2 tension lap length design recommendation is conservative.
\end{abstract}

\section{Keywords}

Lap length, reinforced concrete, finite element analysis, Eurocode 2, failure modes, normal stress

\subsection{INTRODUCTION}

The flexural capacity of a reinforced concrete beam with lapped joints within a tension reinforcement under load with respect to the bond between concrete and the reinforcement is a real source of concern as it is very important to the overall strength and safety of the reinforced concrete beam (Cairns, J., 2016). Since most design codes (Eurocode, American Concrete institute etc) specify various requirements for the design of the minimum required lap length for a certain reinforcement bar diameter. Several factors have been attributed to the failure of the lap joints such as inadequate concrete cover, bond between concrete and reinforcement, lap lengths, concrete compressive and tensile strength (Lagier et al., 2015). This identified factors are also in line with the requirements as specified by Eurocode 2. However, the conservative nature of EC2 requirements for the design of column compression lapped joints have been 
recently questioned by several researchers through laboratory experiments with many claims of over design (8\% more than lap length required) in analysis leading to a marginal increased cost of construction for the designed structure (Cairns T., 2016; Cairns and Eligehausen., 2014). This then prompted a closer consideration into the tension lap length required for a reinforced concrete beam by EC2. Several researchers have embarked on various amount of investigations as to the flexural behaviour and capacity of reinforced concrete beam with laps positioned at the tension reinforcement zone. Although the focus of this research is on EC2 designs, yet it is worthy of note to understand the findings of other researchers, which was carried out mainly as a laboratory experiment using other type of design codes. Mousa (2015), on the flexural behaviour and ductility of high strength concrete beam with tension lap splice using the American code $(\mathrm{ACl})$, found that the bond strength of the lapped reinforcement bars is mainly dependent on the concrete cover, reinforcement lap-length, diameter of reinforcement bar, surface of reinforcement bar, yield strength of steel and the shape of reinforcement lap ends. Abdel-Kareem et al., (2015) confirmed that adequate concrete and reinforcement bar bond is an essential phenomenon in the design of reinforced concrete structures. Studies conducted by Lagier et al., (2015) on the bond strength of tension lap splice specimen in ultra-high performance fibre reinforced concrete using the Canadian design code, suggests that splitting failure in concrete beams due to reinforcement laps could be attributed to inadequate tensile properties of the concrete cover, which is a function of the overall strength of the concrete. The closest to the evaluation of EC2 requirements for lapped reinforcement was carried out by Cairns (2016) on column compression lap joints, discovering that concrete cover is very critical to a column compression lap joint failure and suggests a minimum concrete cover equivalent to the diameter of the main reinforcement bars being used. He also found out that the EC2 is about $8 \%$ more than the required for a column compression lap length, thereby raising our curiosity on tension lap length design for reinforced concrete beams.

Previous works on several design codes (ACl, Canadian code and EC2) have all shown that the flexural capacity of a beam with respect to bond strength of the lapped reinforcement is a function of the concrete cover, steel yield strength, concrete strength and reinforcement bar size. Yet very little or no work has been done in evaluating the EC2 lap length designs either as a laboratory experiment or computational research work. However, Islam et al., (2014) successfully carried out a Finite Element Analysis of Steel Fiber Reinforced Concrete (SFRC): Validation of Experimental Shear Capacities of Beams using the ANSYS finite element analysis software (ANSYS, 2014), and suggested that the shear capabilities of an SFRC structure can be successfully predicted using the FEA analysis. For concrete under point load, splitting crack occurs at compressive stress level under the loading area significantly much higher than in case of line load (Boye et al., 2019). However, the use of FEA provides near actual behavior of materials such as concrete and cement-soil columns depending on loading conditions (Boye et al., 2018). Hu et al., (2004) and Al-ta'an et al., (2010) all successfully carried out various forms of computational researches using the ANSYS and ABAQUS Finite Element Analysis (FEA) software on the Finite Element Analysis Of Steel Fibre Reinforced Concrete (SFRC): validation of experimental shear capacities of beams; Nonlinear Finite Element Analysis Of Reinforced Concrete Beams Strengthened By Fibre-Reinforced Plastics and Nonlinear Three Dimensional Finite Element Analysis Of Steel Fibre Reinforced Concrete Deep Beam respectively. Showing that there is a potential for an accurate and successful analysis of the EC2 requirements for a tension reinforcement lap length design in this research.

Since most of the identified research are laboratory experiment based, and their results limited to the number of specimens (beam) that where been tested and laboratory conditions surrounding the test (preparation and placement of the concrete, material strength of the reinforcement etc) which is obviously expensive and not sustainable (due to the mass production of concrete). There has been no investigation on the evaluation of the EC2 requirements for tension lap lengths $\left(I_{0}\right)$ in a reinforced concrete beam. This research investigates the EC2 tension lap lengths $\left(I_{0}\right)$ design in a normally reinforced concrete beam, using the ANSYS software for a finite element beam by simulating a laboratory 4-point beam loading test system under static loading till failure (See Figure 1 and 2). Without any laboratory work using an innovative and sustainable finite element approach devoid of the rigorous, costly and less sustainable laboratory works. And suggests an expected safety margin (lap length) against flexural failure with regards to their failure load, tensile stress and compressive stress on the reinforced concrete beam for tension reinforcement diameters $10 \mathrm{~mm}, 12 \mathrm{~mm}, 16 \mathrm{~mm}$, $20 \mathrm{~mm}$ and $25 \mathrm{~mm}$ respectively. The factors utilised in this computational research according to EC2 are the concrete design tensile strength $\left(f_{c t d}\right)$, reinforcement bar diameter $\left(d_{b}\right)$, yield strength of the steel $\left(f_{y k}\right)$, concrete cover $\left(c_{d}\right)$ and the shape of the reinforcement bar $\left(\alpha_{1}\right)$. 


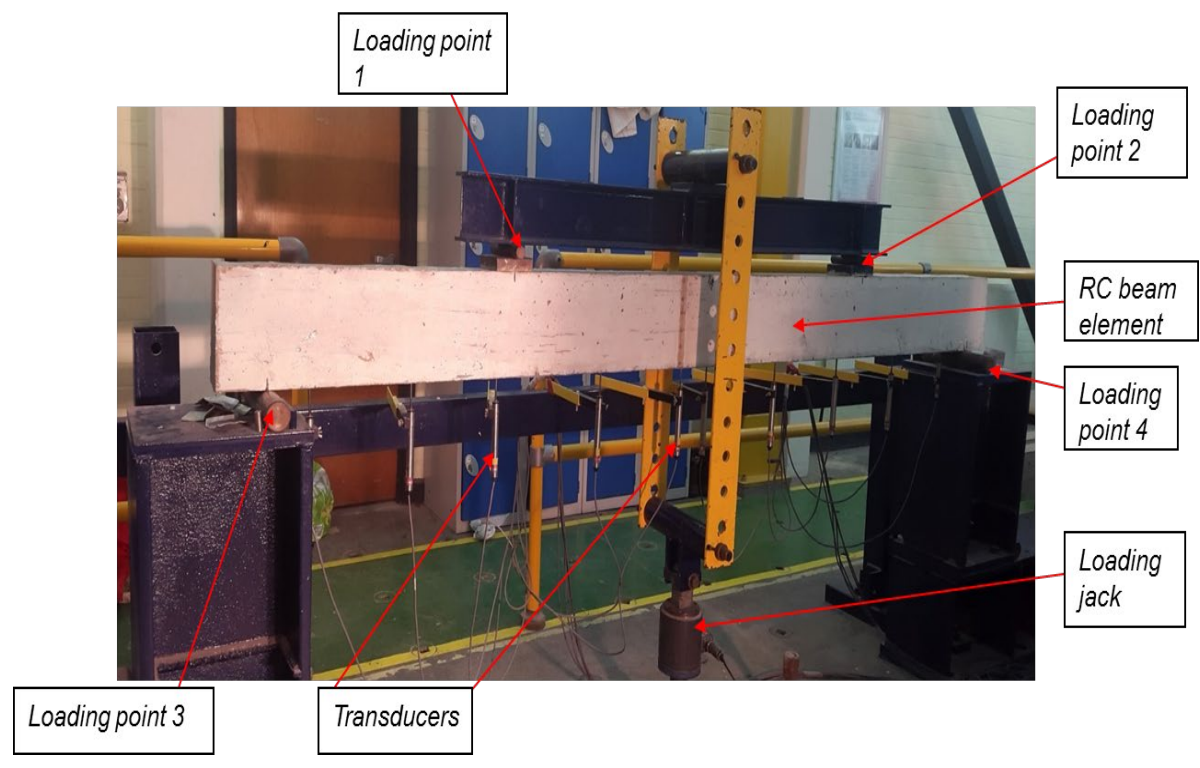

Figure 1: Typical laboratory 4-point beam loading system.

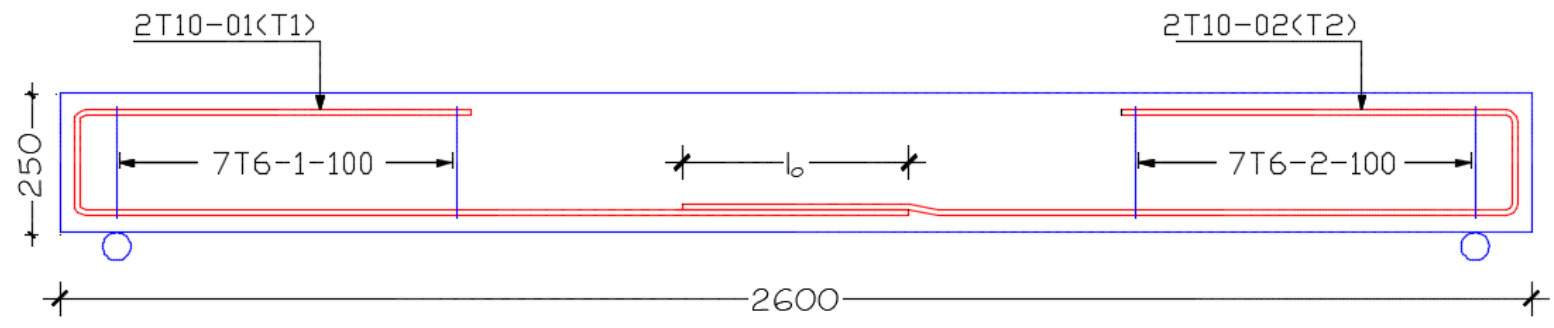

Figure 2: Typical reinforcement lap length $\left(I_{0}\right)$ position and beam layout.

\subsection{EC2 REINFORCEMENT LAP LENGTH DESIGN}

The main variables that affects the reinforcement lap length design as stated by EC2 are listed below with the adopted corresponding values for the present study.

- $\quad$ Characteristics yield strength of steel, $f_{\mathrm{yk}}\left(500 \mathrm{~N} / \mathrm{mm}^{2}\right)$

- Diameter of tension reinforcement bar, $d_{b}(10 \mathrm{~mm})$

- Ultimate uniaxial tensile cracking strength of concrete, $\mathrm{f}_{\mathrm{ctd}}\left(3 \mathrm{~N} / \mathrm{mm}^{2}\right)$

- $\quad$ Concrete cover, $\mathrm{c}_{\mathrm{d}}(25 \mathrm{~mm})$

\subsection{EC2 lap length reinforcement design Sample calculation}

According to BS EN 1992-1-1:2004+A1:2014, the design for the required lap length, $\mathrm{I}_{0}(\mathrm{~mm})$ in a tension bar reinforcement can be seen below in Equation 1.

$t_{0}=\alpha_{1} \alpha_{2} \alpha_{3} \alpha_{5} \alpha_{6} l_{\text {b.reqd }} \geq t_{0 . \min }$

Taking the $10 \mathrm{~mm}$ bar as an example, the required lap length, $\mathrm{l}_{0}(\mathrm{~mm})$ will be calculated using equation 2 as follows: For $\alpha_{1}=1$, (for straight reinforcement bar, (EC2))

$\alpha_{2}=\left[1-\frac{0.15\left(c_{d}-d_{b}\right)}{d_{b}}\right] \geq 0.7$ and $\leq 1.0$

Since $\alpha_{2}(0.775) \geq 0.7$ and $\leq 1.0$, the condition is satisfied for $\alpha_{2}$

$\alpha_{3}=\alpha_{5}=1$ (no transverse reinforcement and transvers pressure respectively, (EC2)), $\alpha_{6}=1.4$, (BS EN 1992-1$1: 2004+\mathrm{A} 1: 2014), \sigma_{s d}=434.8 \mathrm{~N} / \mathrm{mm}^{2}$ 
Ultimate bond stress, $f_{b d}=2.25 \eta_{1} \eta_{2} f_{c t d}$

$$
\eta_{1}=1 \text { for good bond (EC2) and } \eta_{2}=1(E C 2) \text {, }
$$

since $d_{b}(10 \mathrm{~mm}) \leq 32 \mathrm{~mm}$, Concrete tensile strength, $f_{c t d}=3 \mathrm{~N} / \mathrm{mm}^{2}$

$$
\text { Ultimate bond stress, } f_{b d}=6.8 \mathrm{~N} / \mathrm{mm}^{2}
$$

Therefore, basic required anchorage length, $l_{\mathrm{b} . \mathrm{regd}}=\left[\frac{d_{b}}{4}\right]\left[\frac{\sigma_{s d}}{f_{b d}}\right]$

Minimum bar length, $l_{\text {o.min }}=\left[0.3 \alpha_{6} l_{b . r e q d} ; 15 \phi ; 200 \mathrm{~mm}\right]$

$[162.9 \mathrm{~mm} ; 150 \mathrm{~mm} ; 200 \mathrm{~mm}]$

$$
l_{o}=\alpha_{1} \alpha_{2} \alpha_{3} \alpha_{5} \alpha_{6} l_{\text {b.reqd }} \geq l_{\text {o.min }}
$$

Where: $\alpha_{1}=1, \alpha_{2}=0.775, \alpha_{3}=1, \alpha_{5}=1, \alpha_{6}=1.5$, $l_{\text {b.reqd }}(\mathrm{mm})=36.2 d_{b}$

Since $l_{o}(421.2 \mathrm{~mm}) \geq l_{\text {o.min }}[162.9 \mathrm{~mm} ; 150 \mathrm{~mm} ; 200 \mathrm{~mm}]$, required lap length is satisfied.

Figure 3 shows reinforcement lap-length $\left(l_{0}\right)$ for a $10 \mathrm{~mm}$ reinforcement bar for the sample calculation provided above and Table 1, shows the corresponding lap lengths of a similar calculations for $12 \mathrm{~mm}, 16 \mathrm{~mm}, 20 \mathrm{~mm}$ and $25 \mathrm{~mm}$ reinforcement bar sizes.

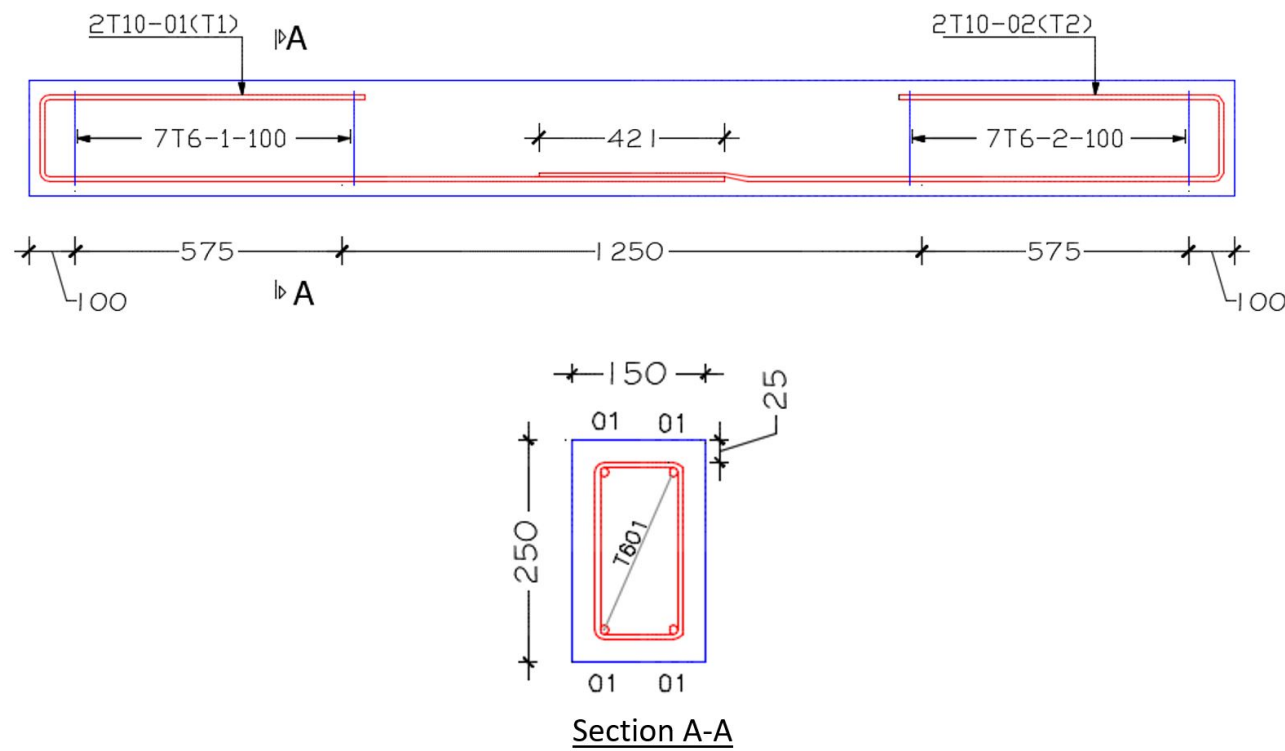

Figure 3: Design reinforcement lap-length $(\mathrm{mm})$ position for $10 \mathrm{~mm}$ tension reinforcement bar diameter diameter

Table 1: Showing the evaluated lap-length design $\left(\mathrm{I}_{\mathrm{o}}\right)$ according to EC2.

\begin{tabular}{cccccc}
\hline Tension bar diameter, $\mathbf{d}_{\mathbf{b}}(\mathbf{m m})$ & $\mathbf{1 0}$ & $\mathbf{1 2}$ & $\mathbf{1 6}$ & $\mathbf{2 0}$ & $\mathbf{2 5}$ \\
\hline Concrete design tensile strength, $\mathbf{f}_{\mathrm{ctd}}\left(\mathbf{N} / \mathbf{m m}^{2}\right)$ & 3.0 & 3.0 & 3.0 & 3.0 & 3.0 \\
Concrete cover, $\mathbf{c}_{\mathbf{d}}(\mathbf{m m})$ & 25 & 25 & 25 & 25 & 25 \\
Steel yield strength, $\mathbf{f}_{\mathbf{y k}}\left(\mathbf{N} / \mathbf{m m}^{2}\right)$ & 500 & 500 & 500 & 500 & 500 \\
Design Lap length, $\mathrm{l}_{\mathbf{0}}(\mathbf{m m})$ & $42.1 d_{b}$ & $45.5 d_{b}$ & $49.8 d_{b}$ & $52.3 d_{b}$ & $54.3 d_{b}$ \\
\hline
\end{tabular}




\subsection{METHODS}

\subsection{Beam description}

The dimensional details of the reinforced concrete beams with varying lap lengths are $2600 \mathrm{~mm}$ length by $250 \mathrm{~mm}$ high by $150 \mathrm{~mm}$ wide with a span to depth ratio of 10.4, while the reinforcement layout is designed for the concrete beam to fail in tension. The test beams were simply supported and simulated using a 4-point loading test system. The load impactors are $100 \mathrm{~mm}$ length by $150 \mathrm{~mm}$ wide by $25 \mathrm{~mm}$ thick metal plate on which static loadings will be applied unto. The supports are $50 \mathrm{~mm}$ diameter by $150 \mathrm{~mm}$ wide solid cylindrical steel (see Figure 4), and $6 \mathrm{~mm}$ reinforcement links were used for all beams at $100 \mathrm{~mm}$ spacing. The main bars (tension reinforcement) were changed for different lap length and reinforcement bar sizes respectively. Table 2 gives details, while Figure 5 shows a pictorial view of the different calculated cases of reinforcement lap length and bar sizes $(12 \mathrm{~mm}, 16 \mathrm{~mm}, 20 \mathrm{~mm}$ and $25 \mathrm{~mm})$ considered in this study.

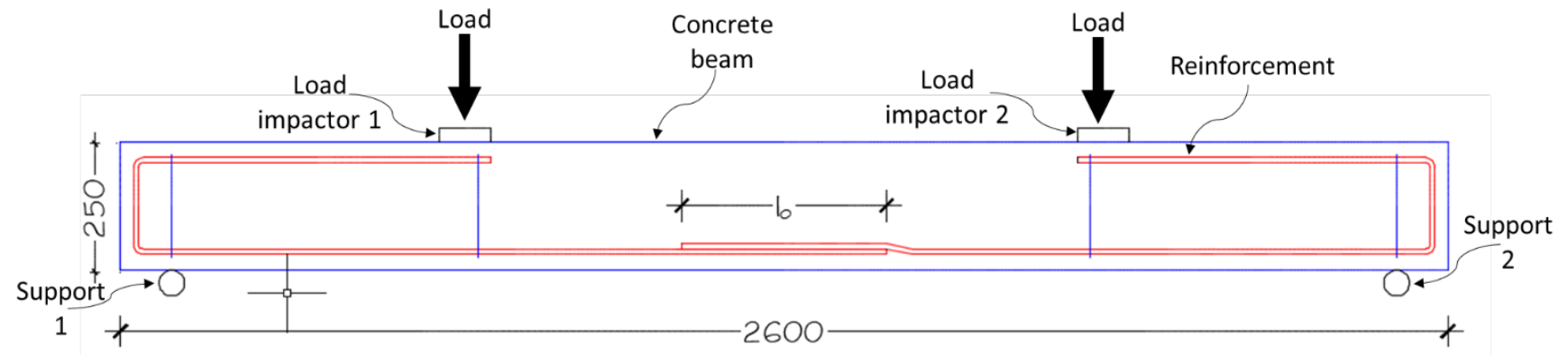

Figure 4: Dimension and details of test beam setup

Table 2: Showing the reinforcement lap-length (lo) cases with respect to bar diameters

\begin{tabular}{|c|c|c|c|c|c|}
\hline \multirow{2}{*}{ Cases } & \multicolumn{5}{|c|}{ Reinforcement Bar Diameters } \\
\hline & $10 \mathrm{~mm}$ & $12 \mathrm{~mm}$ & $16 \mathrm{~mm}$ & $20 \mathrm{~mm}$ & $25 \mathrm{~mm}$ \\
\hline Case 1 (EC 2) control beam & $42.1 d_{b}$ & $45.5 d_{b}$ & $49.8 d_{b}$ & $52.3 d_{b}$ & $54.3 d_{b}$ \\
\hline Case 2 (5\% lap length reduction) & $40.0 d_{b}$ & $43.2 d_{b}$ & $47.3 d_{b}$ & $49.7 d_{b}$ & $51.6 d_{b}$ \\
\hline Case 3 (10\% lap length reduction) & $37.9 d_{b}$ & $41.0 d_{b}$ & $44.8 d_{b}$ & $47.1 d_{b}$ & $48.9 d_{b}$ \\
\hline Case 4 (15\% lap length reduction) & $35.8 d_{b}$ & $38.7 d_{b}$ & $42.3 d_{b}$ & $44.5 d_{b}$ & $46.2 d_{b}$ \\
\hline Case 5 (20\% lap length reduction) & $33.7 d_{b}$ & $36.4 d_{b}$ & $39.8 d_{b}$ & $41.8 d_{b}$ & $43.5 d_{b}$ \\
\hline Case 6 (25\% lap length reduction) & $31.6 d_{b}$ & $34.1 d_{b}$ & $37.3 d_{b}$ & $39.2 d_{b}$ & $40.8 d_{b}$ \\
\hline Case 7 (30\% lap length reduction) & $29.5 d_{b}$ & $31.9 d_{b}$ & $34.8 d_{b}$ & $36.6 d_{b}$ & $38.1 d_{b}$ \\
\hline Case 8 (35\% lap length reduction) & $27.4 d_{b}$ & $29.6 d_{b}$ & $32.3 d_{b}$ & $34.0 d_{b}$ & $35.3 d_{b}$ \\
\hline Case 9 (40\% lap length reduction) & $25.3 d_{b}$ & $27.3 d_{b}$ & $29.8 d_{b}$ & $31.4 d_{b}$ & $32.6 d_{b}$ \\
\hline Case 10 (45\% lap length reduction) & $23.2 d_{b}$ & $25.0 d_{b}$ & $27.4 d_{b}$ & $28.8 d_{b}$ & $29.9 d_{b}$ \\
\hline Case 11 (50\% lap length reduction) & $21.1 d_{b}$ & $22.8 d_{b}$ & $24.9 d_{b}$ & $26.2 d_{b}$ & $27.2 d_{b}$ \\
\hline Case 12 (55\% lap length reduction) & $19.0 d_{b}$ & $20.5 d_{b}$ & $22.4 d_{b}$ & $23.5 d_{b}$ & $24.5 d_{b}$ \\
\hline Case 13 (60\% lap length reduction) & $16.9 d_{b}$ & $18.2 d_{b}$ & $19.9 d_{b}$ & $20.9 d_{b}$ & $21.8 d_{b}$ \\
\hline Case 14 (65\% lap length reduction) & $14.8 d_{b}$ & $15.9 d_{b}$ & $17.4 d_{b}$ & $18.3 d_{b}$ & $19.1 d_{b}$ \\
\hline Case 15 (70\% lap length reduction) & $12.6 d_{b}$ & $13.7 d_{b}$ & $14.9 d_{b}$ & $15.7 d_{b}$ & $16.3 d_{b}$ \\
\hline Case 16 (75\% lap length reduction) & $10.5 d_{b}$ & $11.4 d_{b}$ & $12.4 d_{b}$ & $13.1 d_{b}$ & $13.6 d_{b}$ \\
\hline Case 17 (80\% lap length reduction) & $8.4 d_{b}$ & $9.1 d_{b}$ & $9.9 d_{b}$ & $10.5 d_{b}$ & $10.9 d_{b}$ \\
\hline Case 18 ( $85 \%$ lap length reduction) & $6.3 d_{b}$ & $6.8 d_{b}$ & $7.4 d_{b}$ & $7.9 d_{b}$ & $8.2 d_{b}$ \\
\hline Case 19 (90\% lap length reduction) & $4.2 d_{b}$ & $4.6 d_{b}$ & $4.9 d_{b}$ & $5.2 d_{b}$ & $5.5 d_{b}$ \\
\hline Case 20 (95\% lap length reduction) & $2.1 d_{b}$ & $2.3 d_{b}$ & $2.5 d_{b}$ & $2.6 d_{b}$ & $2.8 d_{b}$ \\
\hline
\end{tabular}




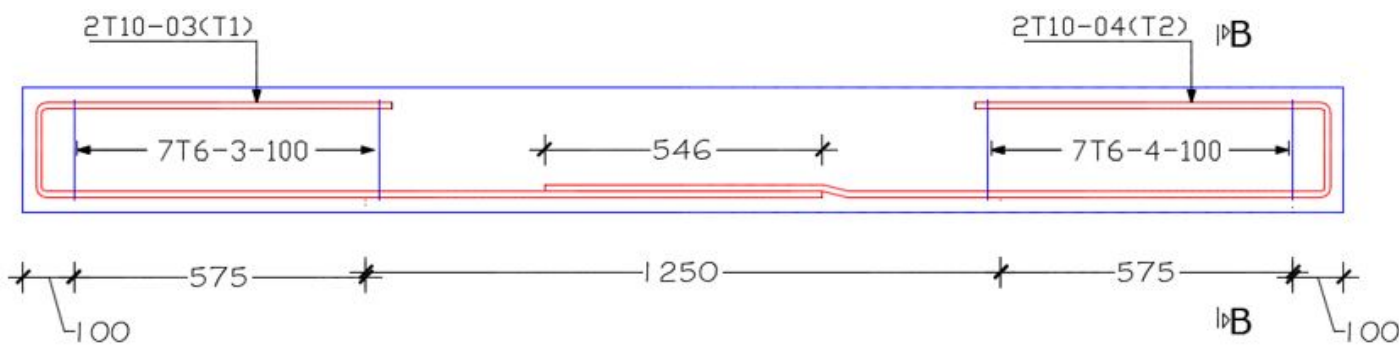

CASE 1 - EC2 Control beam (12mm bar)

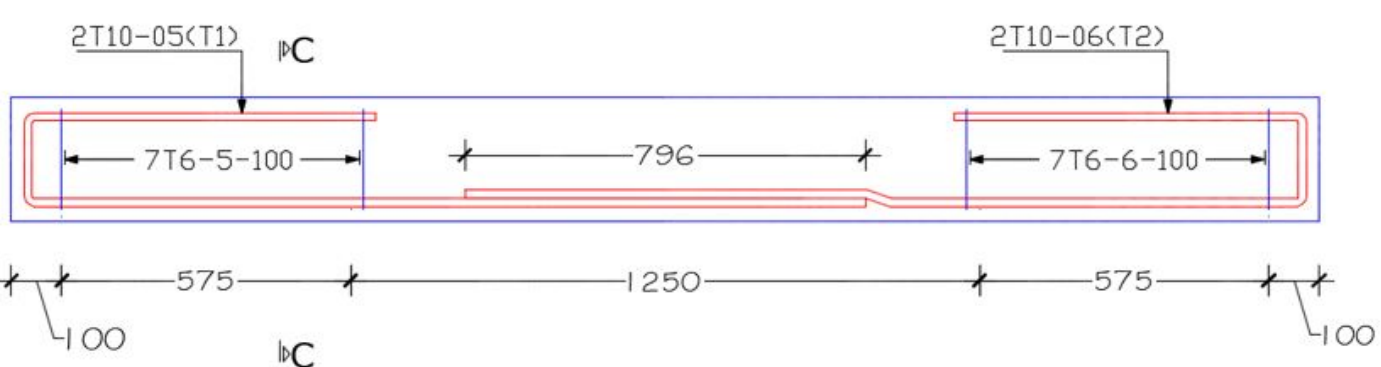

CASE 1 - EC2 Control beam (16mm bar)
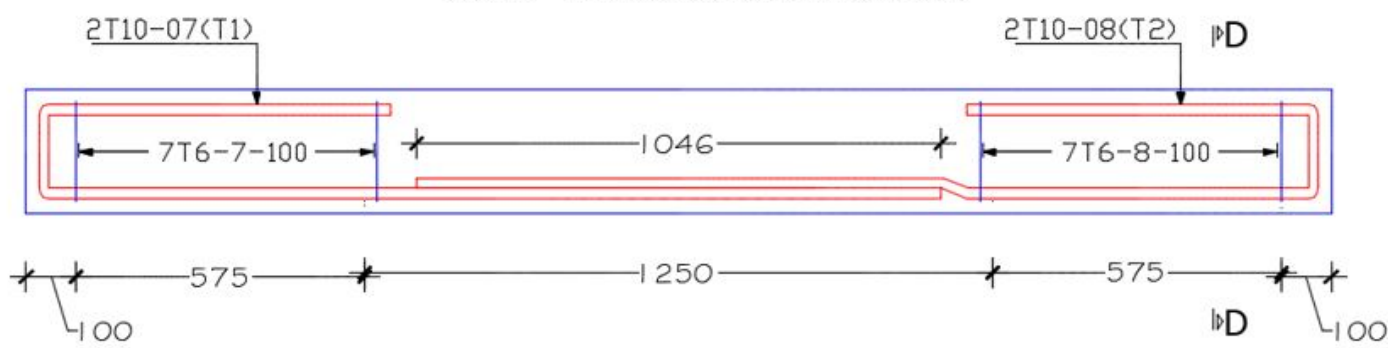

CASE 1 - EC2 Control beam (20mm bar)
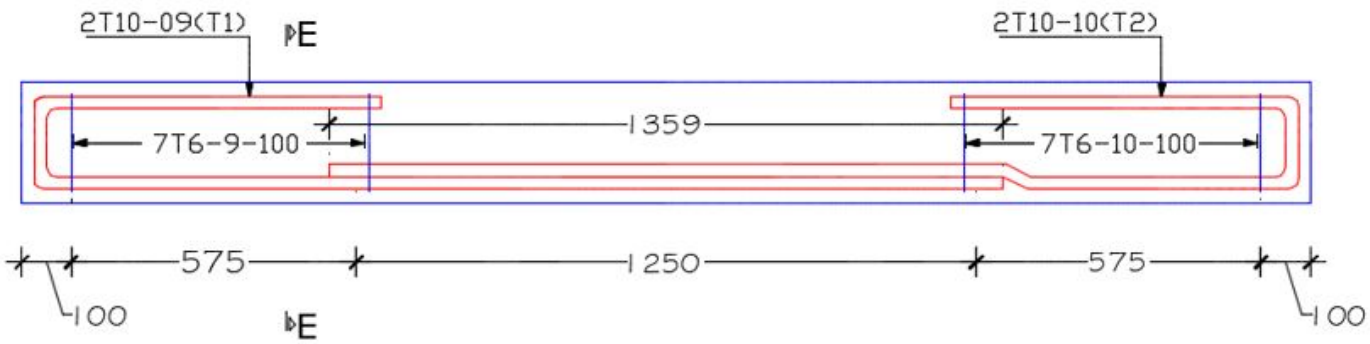

CASE 1 - EC2 Control beam ( $25 \mathrm{~mm}$ bar)

Figure 5: Lap length reinforcement details for EC2 Control beam (12mm, 16mm, 20mm and 25mm)

\subsection{Numerical modelling - Finite element analysis}

Since this a computational analysis subjected to static loading conditions of a reinforced concrete beam, an understanding of a constitutive model is required to reproduce the real behavior of the investigated structure. Constitutive models describe the material responses to different mechanical and/or thermal loading conditions, which provide the stress-strain relations to formulate the governing equations, together with the conservation laws and kinematic relations (Barbato, 2009; Zhang et al., 2017)). With reference to concrete, this is essential for proper investigation of the development, magnitude and direction of stress and strain (mechanical behavior) on the investigated material(concrete) under a given load.The main idea about the Finite Element Analysis (FEA) is the breaking down of a structure under analysis into rectangular or triangular elements of constant thicknesses in which the variation of stress and strain on the element can be obtained due to applied static or dynamic loadings (Adams and Askenazi, 1999). Based on this understanding, the FEA simulation program (ANSYS Workbench) performs series of FEA failure analysis on the identified reinforced concrete beam cases (see Table 2) with respect to their varying reinforcement lap lengths. This is carried out under static loading conditions and a keen observation of the resulting stresses on the reinforced concrete beam. 


\subsubsection{Element type and properties}

The two identified elements used for the simulated test setup are concrete and steel reinforcements (see Figure 4). The concrete material is being identified by the simulation programme (ANSYS workbench) as a SOLID 65 element for its analysis. This SOLID 65 element is composed of eight nodal points with three degree of freedom on the $x, y$ and $z$ direction at each nodal point (see Figure 6). This programme assumes that the SOLID 65 element is initially isotropic and ensures it has the potential of cracking, crushing and plastic deformation in the three orthogonal directions $\mathrm{x}, \mathrm{y}$ and $\mathrm{z}$. According to Cashman and Gopal (2014) "the SOLID 65 element also allows for four dissimilar materials within each element; one matrix material (e.g. Concrete) and a maximum of three other independent reinforcing material e.g. Steel".
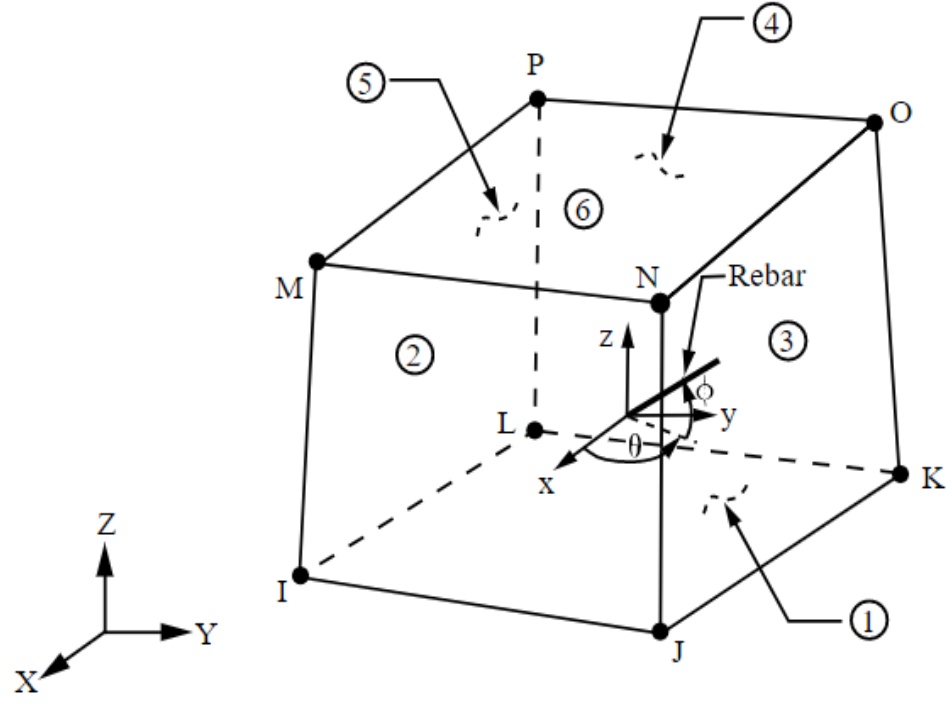

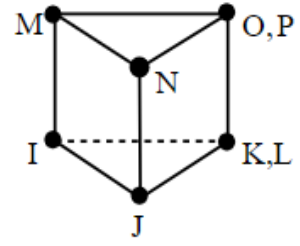

Prism Option

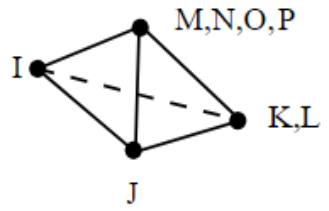

Tetrahedral Option (not recommended)

Figure 6: Shows the geometry of SOLID 65 element in ANSYS workbench 16.0 platform, (Islam et al., (2014)

According to (Olubanwo et al., 2017; 2018), compressive strength and elastic modulus of concrete can be obtained from cylindrical specimens of $200 \mathrm{~mm}$ high by $100 \mathrm{~mm}$ diameter however, the following values as obtained from EC2 shown in Table 3 will be used as the material properties for SOLID 65 concrete element. The open $\left(\beta_{t}\right)$ and closed $\left(\beta_{c}\right)$ shear transfer coefficient determines the extent and amount of shear distributed across the developed cracks in the tested reinforced concrete beam (Si et al., 2008). The shear transfer coefficient values range from 0.0 (no shear transfer) to 1.0 denoting a full shear transfer condition. The current research assumed an open shear transfer coefficient $\left(\beta_{t}\right)$ of 0.2 , while closed shear transfer coefficient $\left(\beta_{c}\right)$ is 0.8 .

Table 3: Showing the concrete element material properties (EC-2)

\begin{tabular}{cc}
\hline Material properties & Values \\
\hline Ultimate characteristics uniaxial compressive strength, $\mathrm{f}_{\mathrm{ck}}$ & $30 \mathrm{~N} / \mathrm{mm}^{2}$ \\
Ultimate uniaxial tensile cracking strength, $\mathrm{f}_{\mathrm{ctd}}$ & $3 \mathrm{~N} / \mathrm{mm}^{2}$ \\
Modulus of elasticity, $\mathrm{E}_{\mathrm{cm}}$ & $27900 \mathrm{~N} / \mathrm{mm}^{2}$ \\
Poisson ratio, $U$ & 0.2 \\
Temperature, $T$ & $22^{\circ} \mathrm{C}$ \\
Open shear transfer coefficient & 0.2 \\
Closed shear transfer coefficient & 0.8 \\
\hline
\end{tabular}

This programme identifies the reinforcement steel bar as a LINK 180 element and it is a 3-D spar element, which was used in the modelling of the reinforcements within the concrete beam. LINK 180 is a uniaxial tension and compression element with an elastic-plastic response, which is made up of 3 nodes with each nodal point having the ability to move in the three orthogonal directions $x, y$ and $z$ (see Figure 7). It is also assumed that the temperature of the LINK 180 element varies along the length of the reinforcement bar. This LINK 180 element can be used to model various structural elements such as springs, trusses, sagging cables, links etc. 

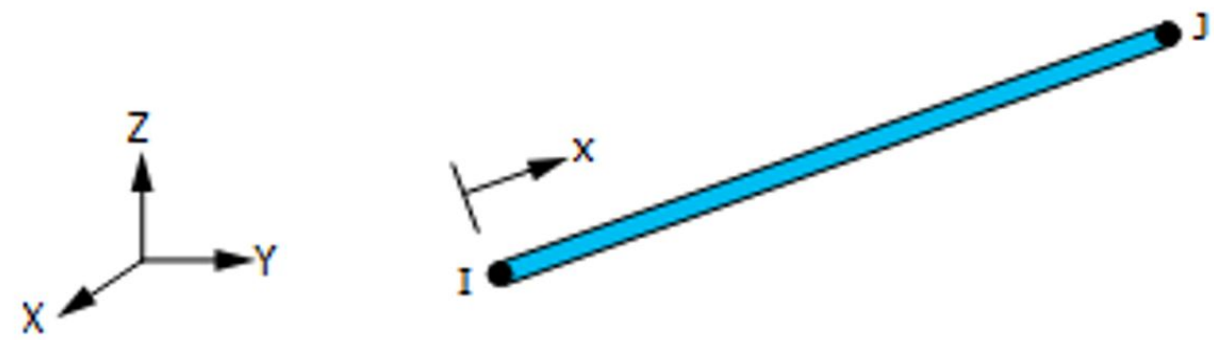

Figure 7: Shows the geometry of LINK 180 element in ANSYS (Cashman and Gopal, 2014).

The steel reinforcement bar used for this research is assumed to be an elastic -perfectly plastic material and identical in tension and compression, (Hu et al., 2004). The material property values used in accordance with EC2 can be shown in Table 4.

Table 4: Showing the LINK 180 steel reinforcement element material properties (EC2)

\begin{tabular}{cc}
\hline Material properties & Values \\
\hline Yield strength, $\mathrm{f}_{\mathrm{yk}}$ & $500 \mathrm{~N} / \mathrm{mm}^{2}$ \\
Modulus of elasticity, $\mathrm{E}_{\mathrm{cm}}$ & $205,000 \mathrm{~N} / \mathrm{mm}^{2}$ \\
Poisson ratio, $U$ & 0.3 \\
Tangent modulus & $2000 \mathrm{~N} / \mathrm{mm}^{2}$ \\
\hline
\end{tabular}

However, it should be noted that the LINK 180 element is treated as an equivalent uniaxial material smeared through the element section and the bond slip between the steel and concrete is not considered in this research.

\subsubsection{Solid modelling of the reinforced concrete beam}

This is the first step in the analysis procedure, where a model generation of various parts of the test beam set-up and reinforcement details (Load impactor 1 and 2, Concrete beam, Support 1and 2, Tension reinforcement bars and Links) as shown in Figure 8 are being built using the "design modeler interface" under the static structural analysis (see Figure 9). It is worthy to also note that although there are various types of techniques for generating a reinforced concrete model (discrete, embedded and smeared) for finite element analysis. This current research employs the discreet technique (Figure 9c), which is based on the assumption that the reinforcement in the discrete model utilizes the reinforcement elements that are linked with concrete mesh nodes. This means that the developed mesh for the reinforcement and concrete shares the identical nodes with both reinforcement and concrete occupying the same region (Srinivasan and Sathiya, 2010).

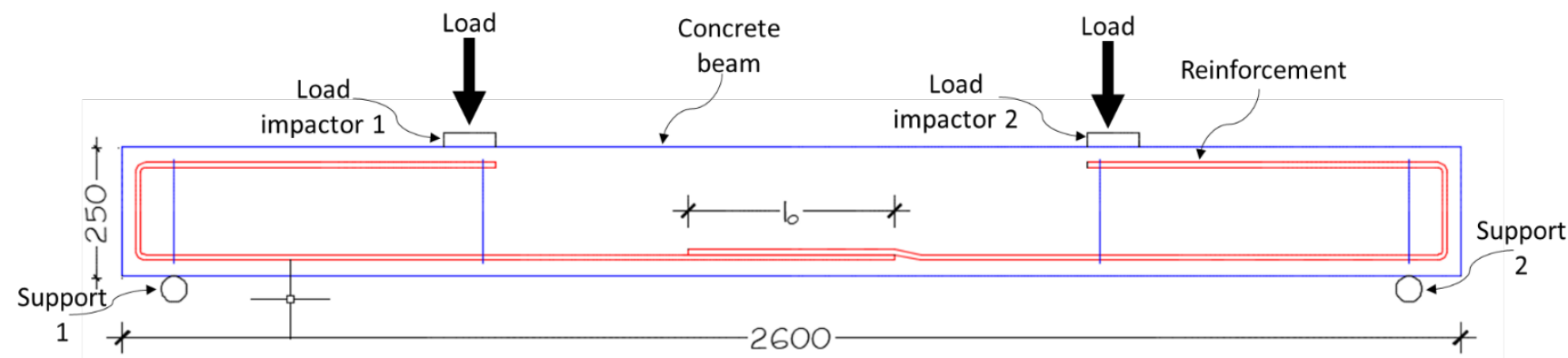

Figure 8: Dimension and details of test beam setup 


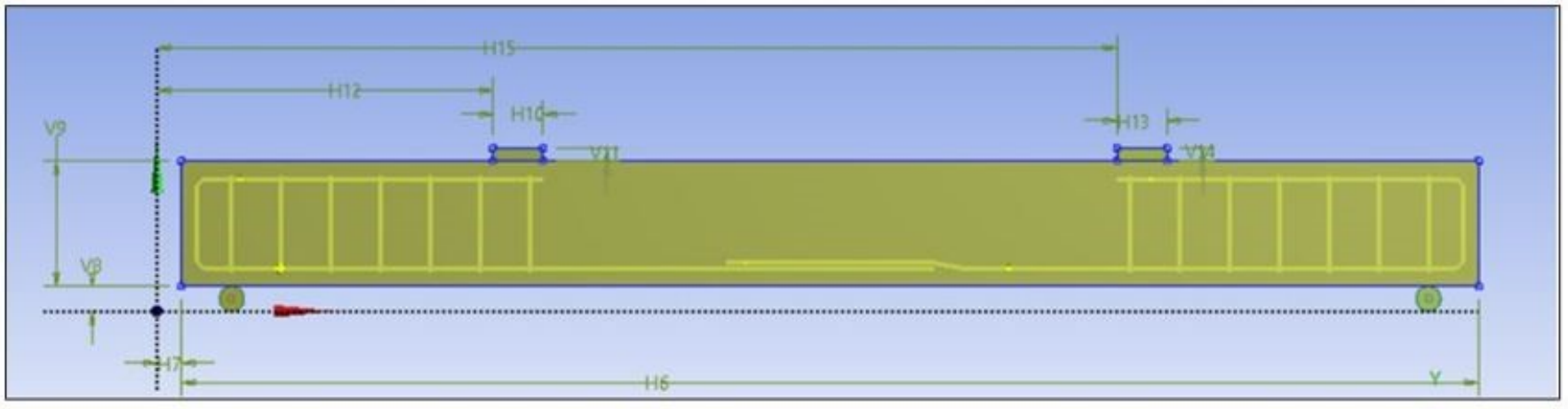

(a)

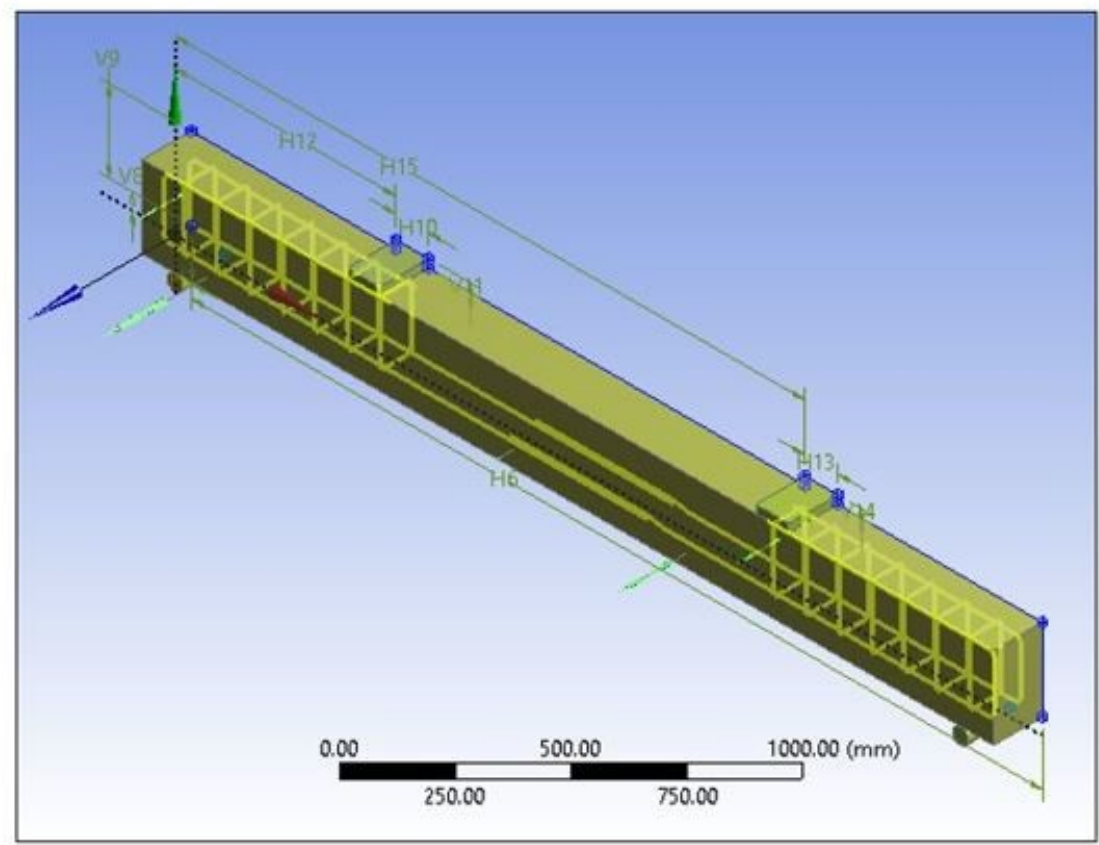

(b)

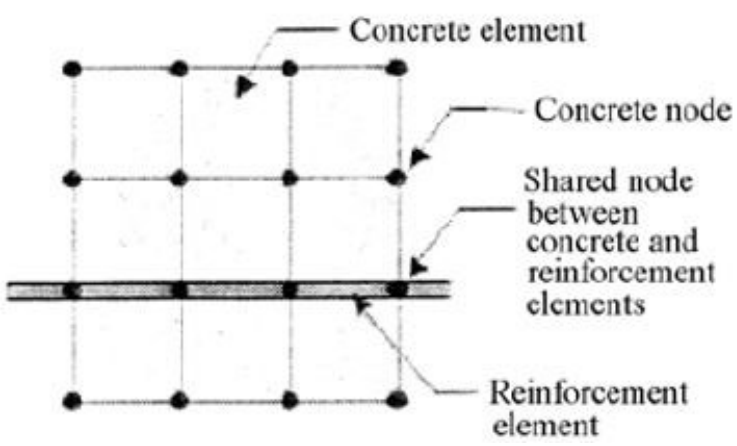

Figure 9: (a) Elevation (b) 3-D view of the modelled test beam- EC2 Control beam (10 mm bar) and (c) Discrete reinforcement model.

The created model in sub-section 3.2.2 is loaded up into the mechanical interface of the ANSYS Workbench simulation program, while an APDL command (ANSYS Parametric Design Language) is used as a subroutine to link and specify the identified element properties for the concrete and reinforcement (Tables 3 and 4 ) into the ANSYS Workbench simulation program (Lawrence, 2006). A contact connection (bonded) is specified between the load impactors 1 and 2 with the concrete beam and supports 1 and 2 with the concrete beam (see Figure 10). So as to bond the identified elements using their respective nodes at their respective point of contacts. While a meshing condition is applied (using a mesh size of $25 \mathrm{~mm}$ ) to break down each element (Load impactor 1 and 2, Concrete beam, Support 1and 2, Tension 
reinforcement bars and Links) into rectangular or triangular elements. So that a Finite Element Analysis (FEA) can be executed on the identified elements (Figure 10).

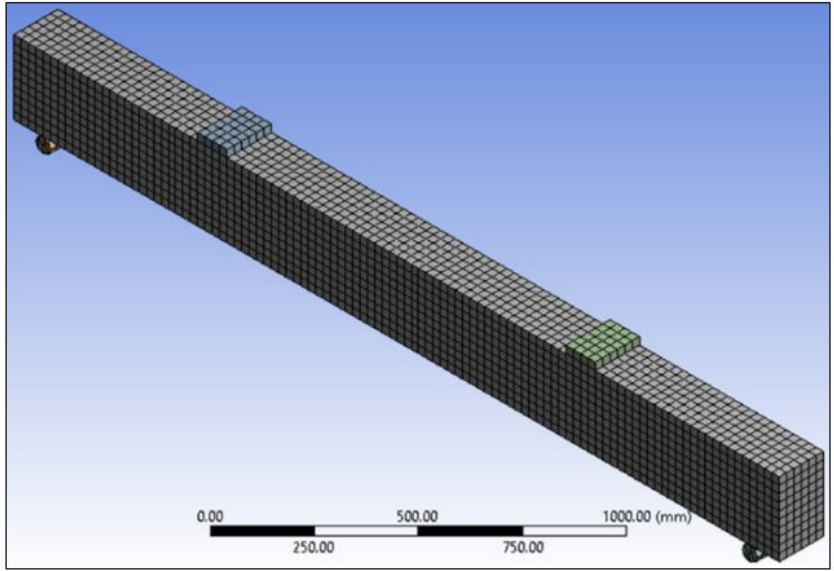

(a)

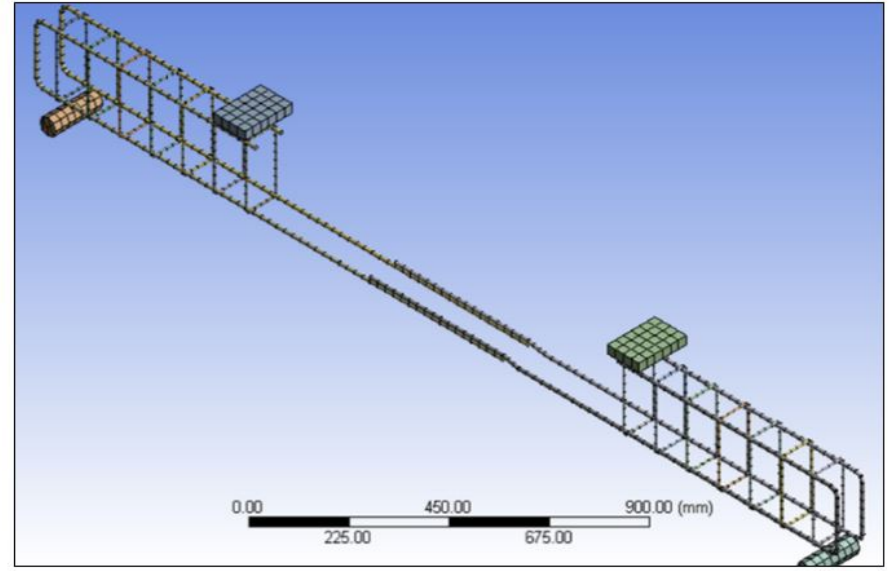

(b)

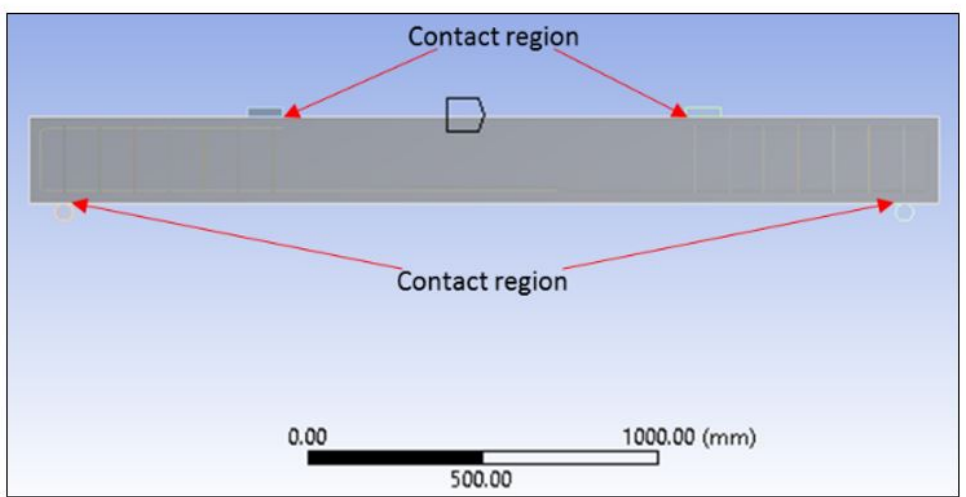

(c)

Figure 10: Meshing of concrete beam (a), reinforcement (b) and contact connection (c) for the test setup elements in case 1 - EC2 Control beam (10mm bar)

\subsubsection{Specify suppot condition and apply loading}

Though the beam test setup indicates a roller support for the identified supports 1 and 2 (see Figure 11). Yet the support conditions in this research will be taken as a pin support (support 1) with no movement in the $\mathrm{x}, \mathrm{y}$ and $\mathrm{z}$ orthogonal directions, while support 2 will be taken as a roller support, where there will be only movement in the $x$ orthogonal direction with no movement in the other directions ( $y$ and $z$ ). A "displacement" support is used in the ANSYS Workbench simulation program to specify all the constraint conditions (see Figure 11). The load impactor is loaded by applying a "force" on each of the load impactors (see Figure 12), while specifying the magnitude and direction of the applied force on the reinforced concrete beam.

\subsubsection{FEA-Analysis}

Using the APDL solver command (/PREP7), the SOLID 65 (concrete) and the LINK 180 (steel reinforcement) elements are connected using all the nodes of the selected elements with a tolerance of 0.001 for analysis, while the APDL solution command "/SOLU" is applied for final FEA analysis. Figure 13 shows the normal stress result output which provides the ultimate compressive and ultimate tensile stress results for the reinforced concrete beams of case 1 - EC2 Control beam for $12 \mathrm{~mm}, 16 \mathrm{~mm}, 20 \mathrm{~mm}$ and $25 \mathrm{~mm}$ reinforcement bar. The failure load $\left(P_{f}\right)$ for the reinforced concrete beams was carried out repeatedly and iteratively by gradually increasing the applied loads on the impactors until the tensile stress in the beam is more than allowable $\left(3 \mathrm{~N} / \mathrm{mm}^{2}\right)$ as specified for the concrete properties (Table 3). 


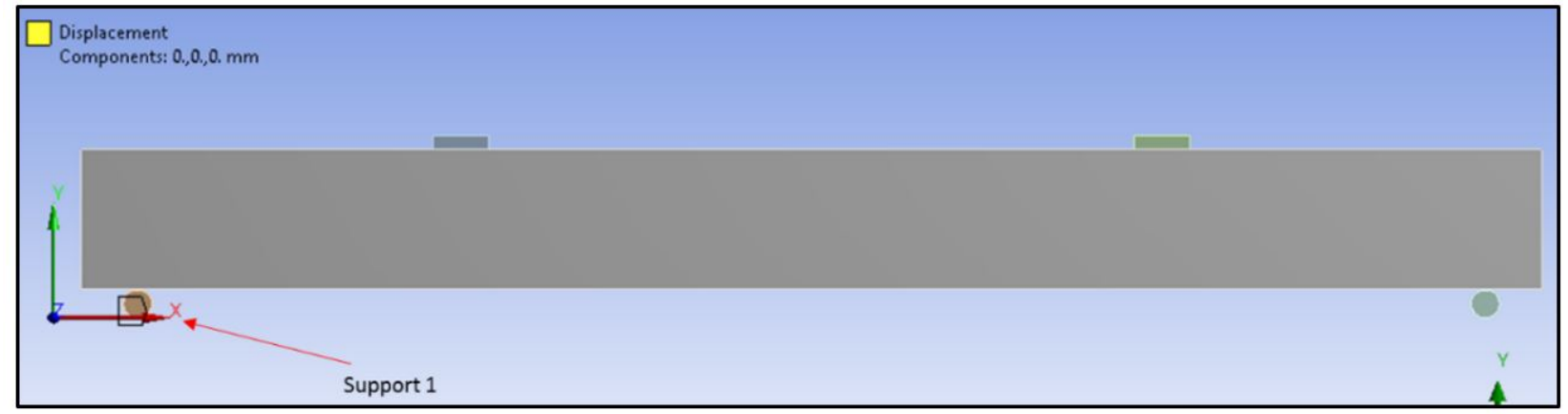

(a)

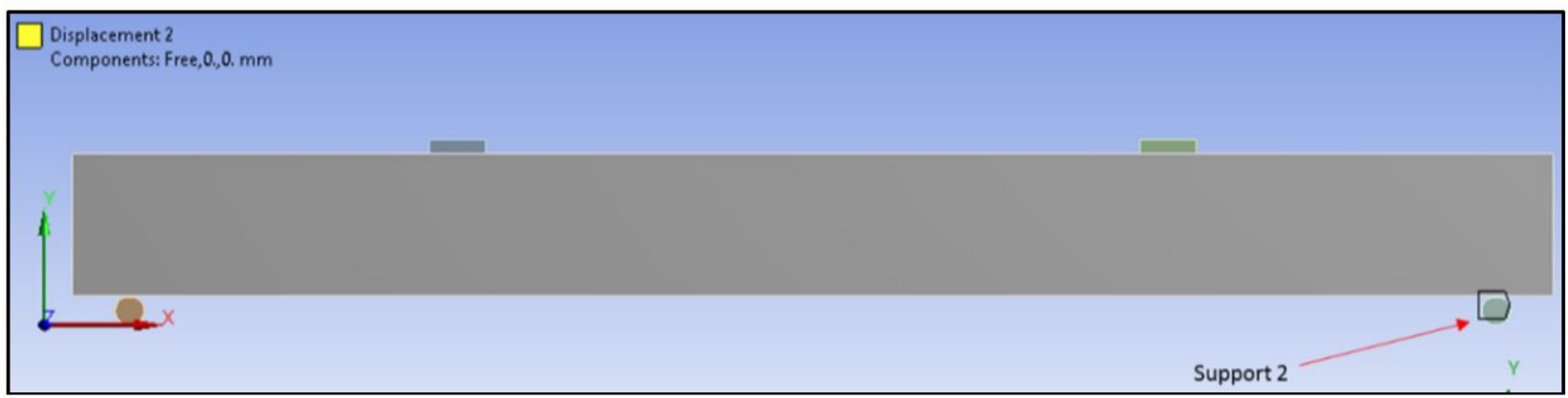

(b)

Figure 11: Support conditions for support 1 (a) and 2 (b) in case 1 - EC2 Control beam (10mm bar)

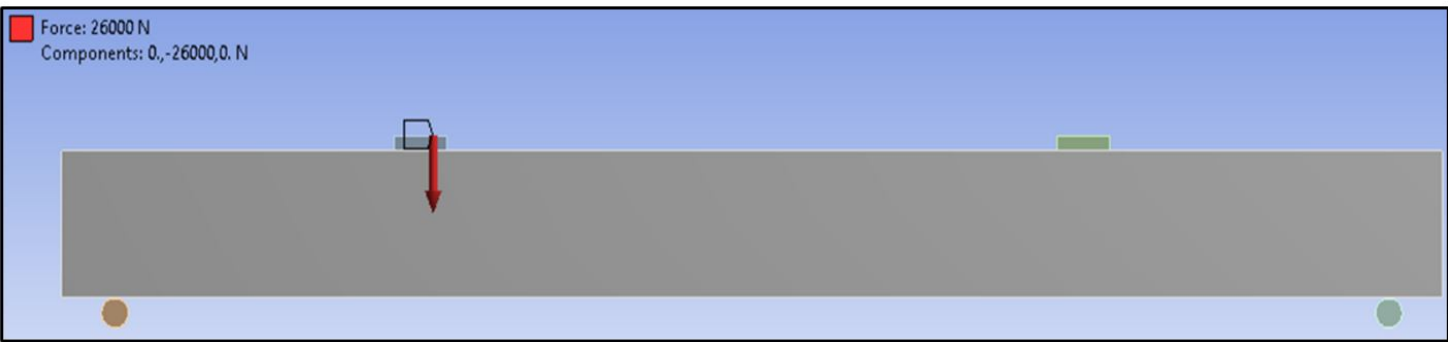

(a)



(b)

Figure 12: Applied force on load impactor 1 (a) and 2 (b) in case 1 - EC2 Control beam (10mm bar)

\subsection{RESULT AND DISCUSSION}

\subsection{Variation in concrete beam failure types}

The compressive stress limit of $30 \mathrm{~N} / \mathrm{mm}^{2}$ for each obtained compressive stress for case 1 (EC2) control beam with reinforcement bar diameter $10 \mathrm{~mm}, 12 \mathrm{~mm}, 16 \mathrm{~mm}$ and $20 \mathrm{~mm}$ was not exceeded. However, case 1 (EC2) control beam with reinforcement bar diameter $25 \mathrm{~mm}$ exceeded the compressive stress limit of $30 \mathrm{~N} / \mathrm{mm}^{2}$. This clearly indicates a tensile failure for the reinforced concrete beam for case 1(EC2) control beam using reinforcement bar diameters $10 \mathrm{~mm}$, $12 \mathrm{~mm}, 16 \mathrm{~mm}$ and $20 \mathrm{~mm}$ (see Figure 14,15,16 and 17). The obtained stresses at failure load for case 1 (EC2) control beam 
with reinforcement bar diameter $10 \mathrm{~mm}, 12 \mathrm{~mm}, 16 \mathrm{~mm}, 20 \mathrm{~mm}$ and $25 \mathrm{~mm}$ are all within the tensile stress limit of $3 \mathrm{~N} / \mathrm{mm}^{2}$ as presented in Figure 18. While the reinforced concrete beam for case 1(EC2) control beam using reinforcement bar diameters $25 \mathrm{~mm}$ failed in compression. It should also be noted that the compression failure experienced by the reinforced concrete beam for case 1 (EC2) control beam using reinforcement bar diameters $25 \mathrm{~mm}$ might be due to overreinforcement of the tension zone, which is largely more than the maximum amount of reinforcement (4\%) required for the tension reinforcement in a concrete beam (Draycott, T. and Bullman, P., 2009). Therefore, since this research is based on loading a reinforced concrete beam to a tensile failure with the test beam reinforcement details designed to fail in tension (Figure 2). Further analysis on other reduction cases was discontinued as the beam will require an increase in the reinforced concrete beam sizes, which will defeat our aim of using uniform parameters in the analysis of all the reinforced concrete beams.

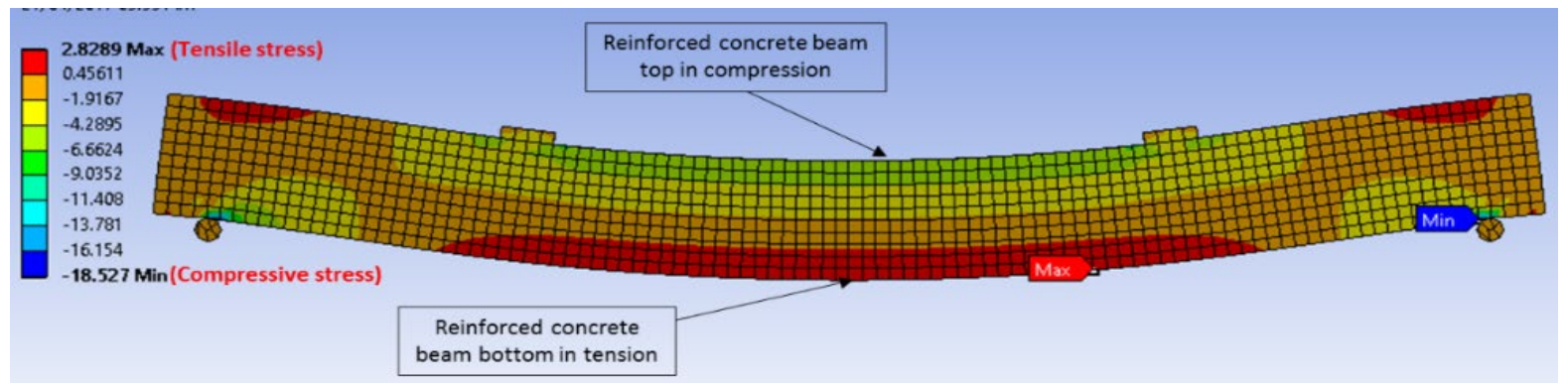

Figure 13: Normal stress result output for case 1 - EC2 Control beam (10mm bar)

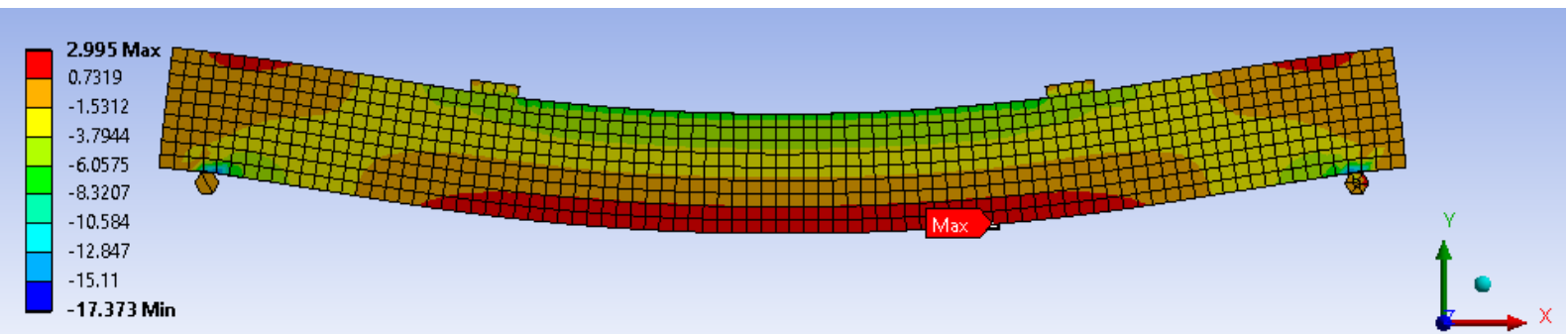

Figure 14: Normal stress result output for case 1 - EC2 Control beam (12mm bar)

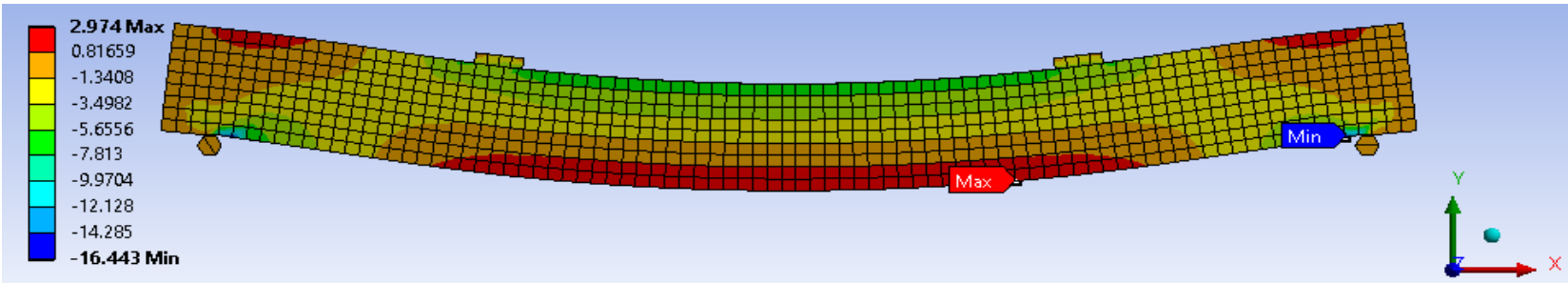

Figure 15: Normal stress result output for case 1 - EC2 Control beam (16mm bar)

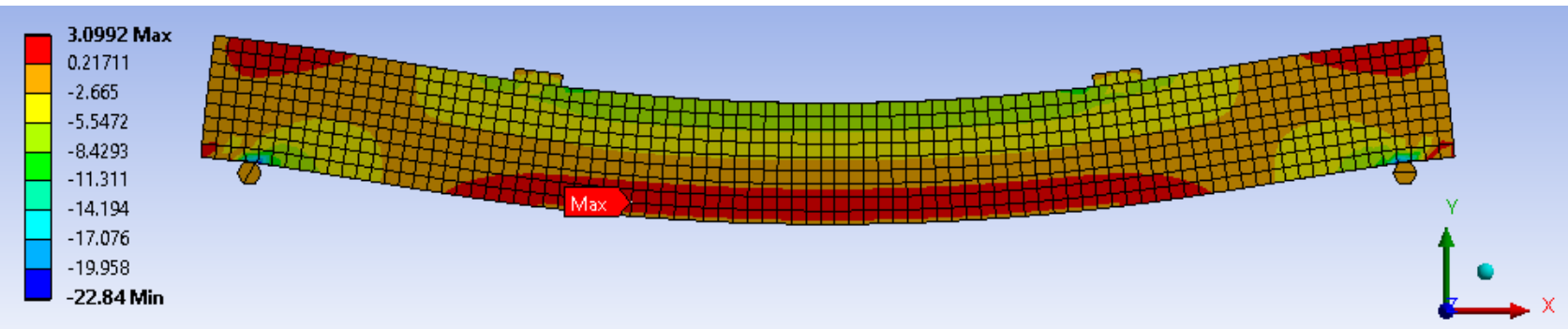

Figure 16: Normal stress result output for case 1 - EC2 Control beam (20mm bar) 


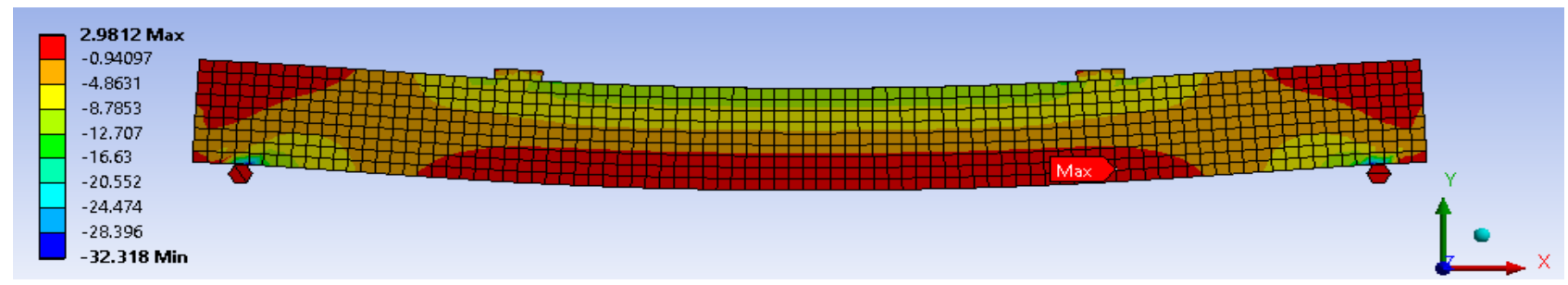

Figure 17: Normal stress result output for case 1 - EC2 Control beam (25mm bar)

\subsection{Effects of failue load on lap length reductions}

Figure 18, 19, 20, 21 and 22 shows the failure loads against the lap lengths for reinforcement bar diameters 10mm, $12 \mathrm{~mm}, 16 \mathrm{~mm}$ and $20 \mathrm{~mm}$ respectively. It was discovered that there is a gradual reduction in the failure load for every $5 \%$ reduction in lap lengths for all the reinforcement bar diameters. The failure loads obtained for case 1(EC2) control beam was consistent with cases $2,3,4$ and 5 of $5 \%, 10 \%, 15 \%$ and $20 \%$ lap length reduction for $10 \mathrm{~mm}$ and $20 \mathrm{~mm}$ reinforcement bar diameters respectively (see figure 19 and 21). Also, the obtained failure loads for case 1(EC2) control beam was consistent with cases $2,3,4,5$ and 6 of $5 \%, 10 \%, 15 \%, 20 \%$ and $25 \%$ lap length reduction respectively for $12 \mathrm{~mm}$ and $16 \mathrm{~mm}$ reinforcement bar diameters (see figure 20 and 21). This observed trend of reduction in failure loads due to lap length reduction could be attributed to the reduction in the percentage amount of reinforcement required within the tension zone of a lapped tension reinforcement (BS EN 1992-1-1:2004+A1:2014). Lagier et al., (2015) suggested that this experienced reduction in failure loads could be attributed to the reduction in bond strength obtained as a result of the interaction between the concrete and the reinforcement bar based on the required contact surface area. Therefore, any reduction in the contact surface area as result of the reduction in lap length will result in the reduction in the bond strength of the lapped reinforcement. An experimental research study carried out by El-Azab and Mohamed (2014) on the effect of tension lap splice on the behaviour of high strength concrete (HSC) beams also recorded that the experienced gradual reduction in failure load could also be due to longitudinal cracks that develops at the tension zone of a reinforced concrete beam with lapped reinforcement which then leads to beam failure. Therefore, a constant monitoring of the crack propagation is advised. El-Azab and Mohamed (2014) also suggested that the use of fibres as an additive in the concrete mix will reduce the propagation of cracks which will ultimately increase the failure load of the reinforced concrete beam.

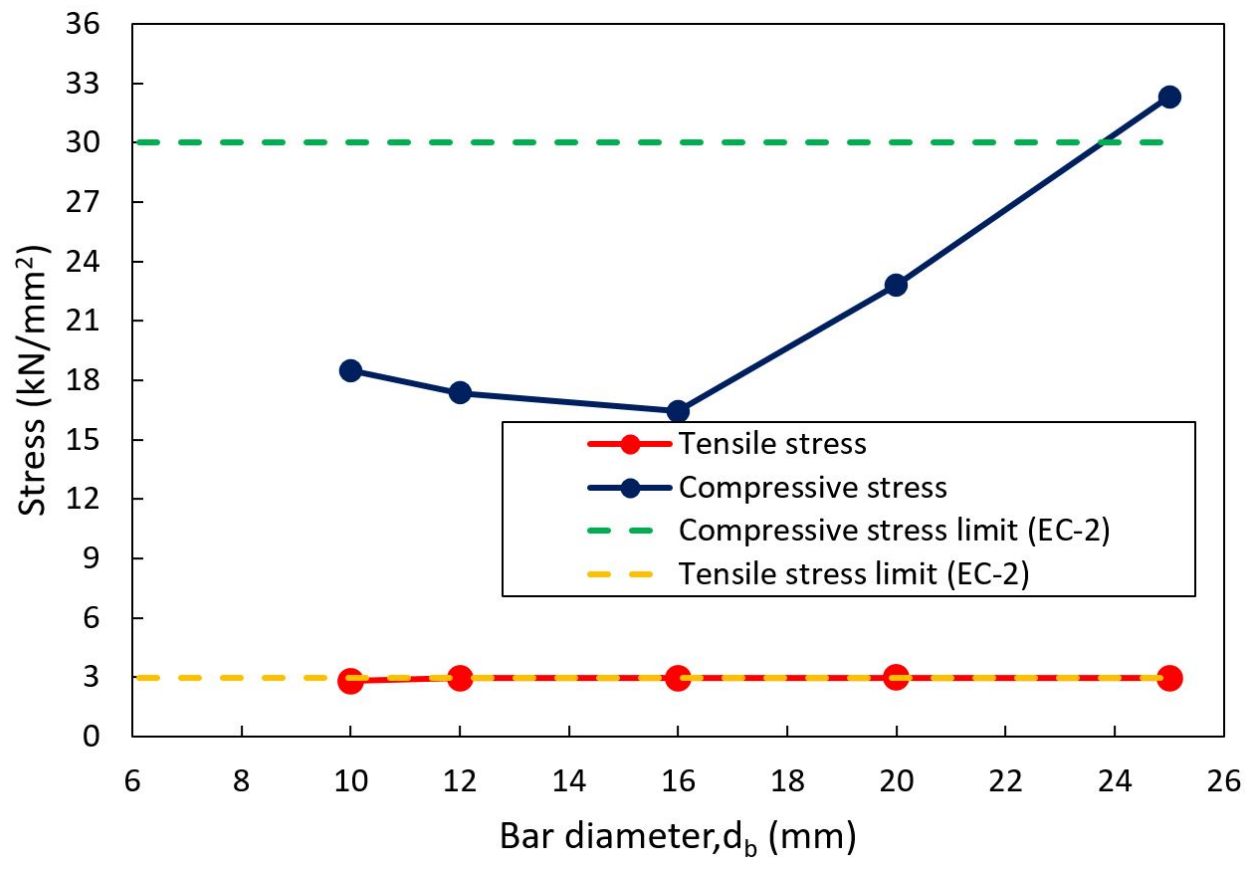

Figure 18: lap length $(\mathrm{mm})$ failure modes 


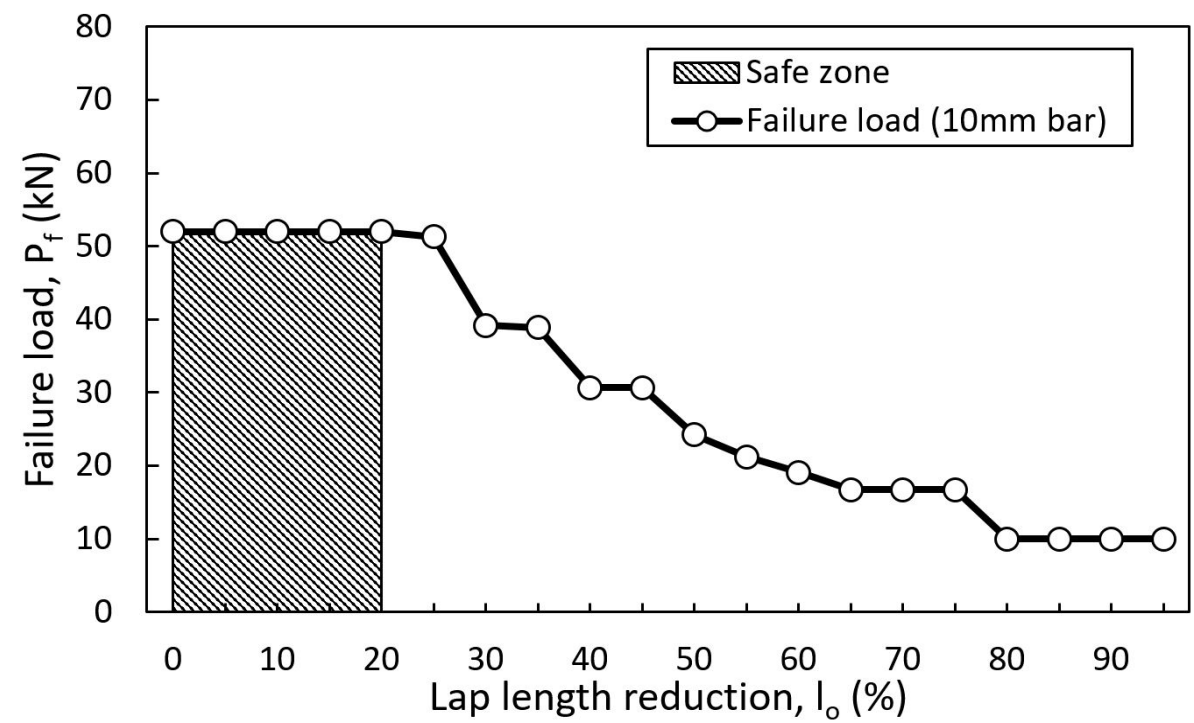

Figure 19: Failure load $(\mathrm{kN})$ against lap length reductions $(\mathrm{mm})$ for $10 \mathrm{~mm}$ reinforcement bar diameter

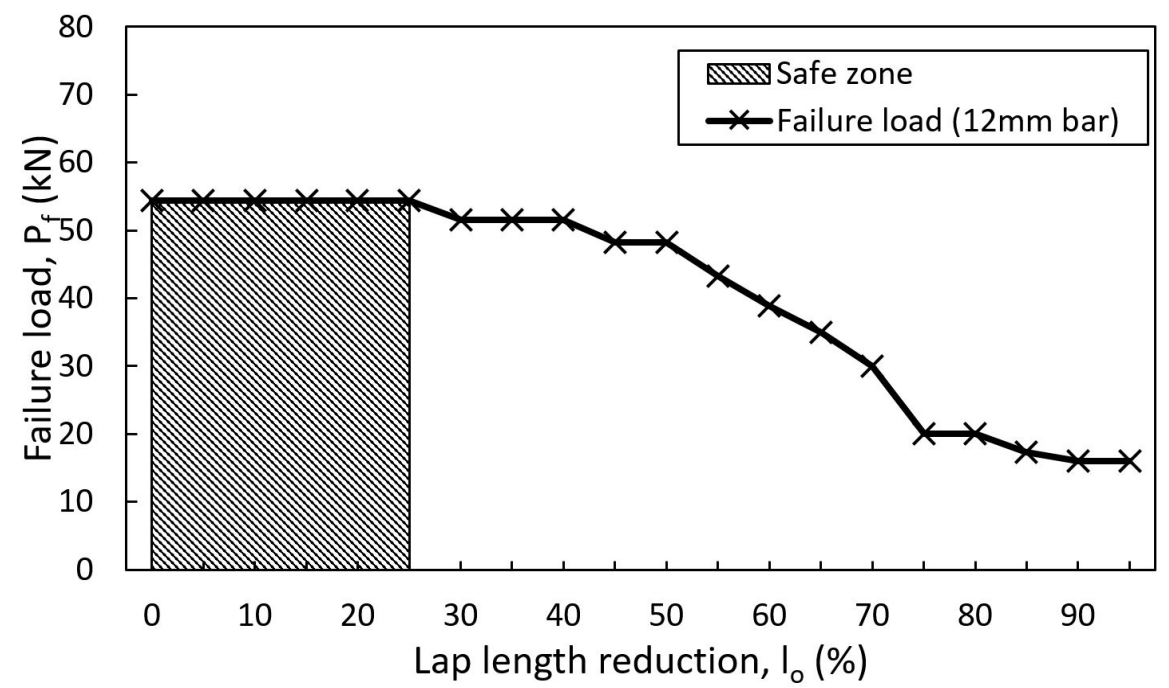

Figure 20: Failure load $(\mathrm{kN})$ against lap length reductions $(\mathrm{mm})$ for $12 \mathrm{~mm}$ reinforcement bar diameter

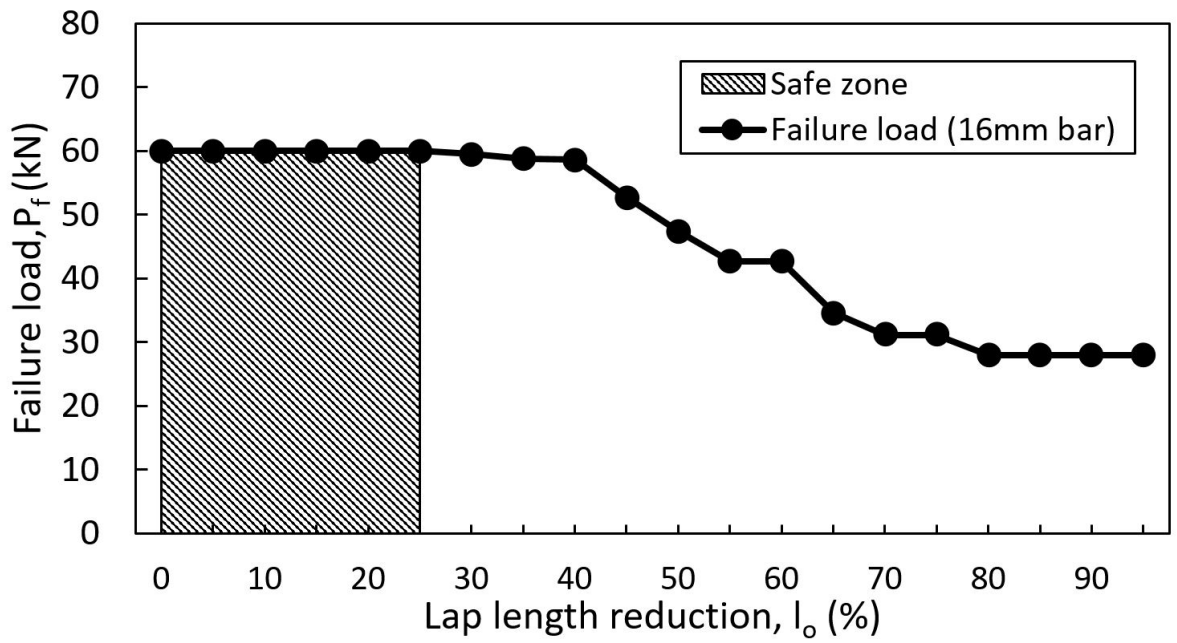

Figure 21: Failure load $(\mathrm{kN})$ against lap length reductions $(\mathrm{mm})$ for $16 \mathrm{~mm}$ reinforcement bar diameter 


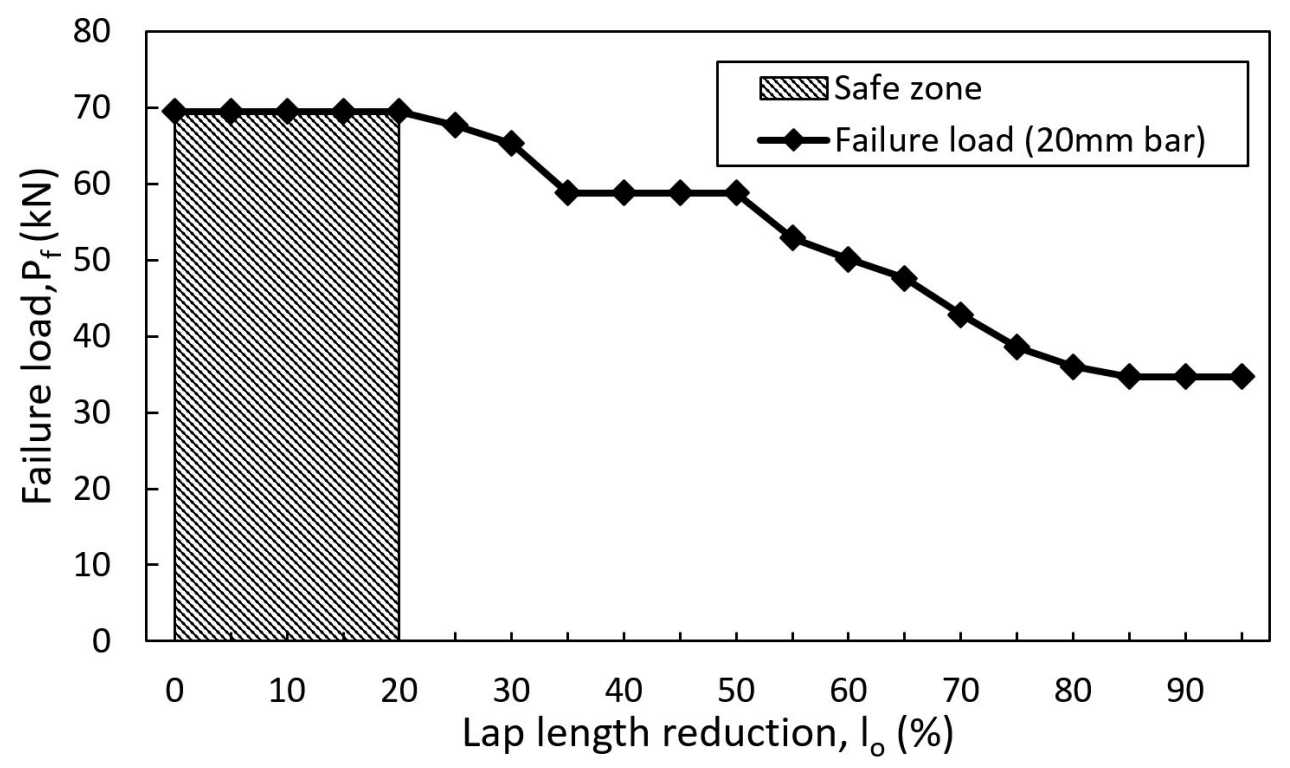

Figure 22: Failure load $(\mathrm{kN})$ against lap length reductions $(\mathrm{mm})$ for $20 \mathrm{~mm}$ reinforcement bar diameter

\subsection{Effects of change in reinforcement bar diameter}

The relationship between reinforcement bar diameter $\left(d_{b}\right)$ and tension lap length $\left(l_{0}\right)$ shows that a linear relationship exists between the reinforcement bar diameter $\left(d_{b}\right)$ and the lap length (see Figure 23 ). This means that for every increase in steel reinforcement bar sizes, there is a corresponding increase in the obtained tension lap length for a reinforced concrete beam. It can also be suggested that the steel reinforcement diameter sizes possess an effect on the overall tensile strength of a reinforced concrete beam. Balazs et al. (2014) also corroborated the above findings based on their various researches which suggests that steel reinforcement bar sizes exert a significant influence on the tension lap length, which is a function of its lap strength. This is however opposed to compression lap lengths, where the steel diameter does not have a considerable influence on the compressive strength of a reinforced column because steel is very good in tension and weak in compression, while concrete is good in compression and weak in tension (Cairns, 2016).

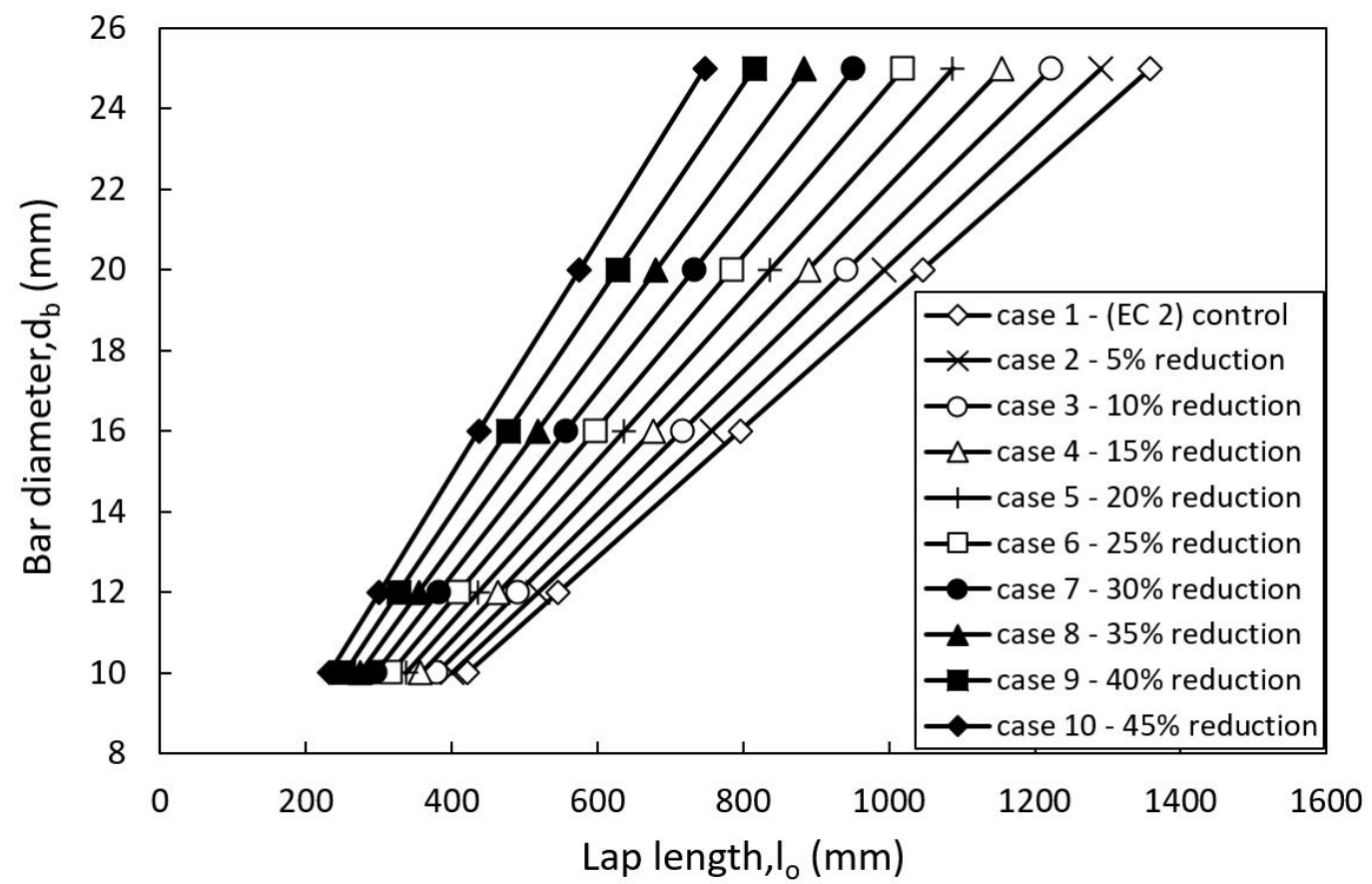

Figure 23: Relationship between the reinforcement bar diameter $(\mathrm{mm})$ with lap length $(\mathrm{mm})$ for $10 \mathrm{~mm}$ reinforcement bar 
Table 5: Optimum lap length $(\mathrm{mm})$

\begin{tabular}{cccc}
\hline Bar diameter (mm) & Control (EC 2) lap length & $\begin{array}{c}\text { Optimum lap length without } \\
\text { 5\% safety }\end{array}$ & $\begin{array}{c}\text { Chosen optimum lap length } \\
\text { with 5\% safety }\end{array}$ \\
\hline $10 \mathrm{~mm}$ & 421 & 337 & 358 \\
$12 \mathrm{~mm}$ & 546 & 410 & 437 \\
$16 \mathrm{~mm}$ & 796 & 597 & 637 \\
$20 \mathrm{~mm}$ & 1046 & 837 & 889 \\
\hline
\end{tabular}

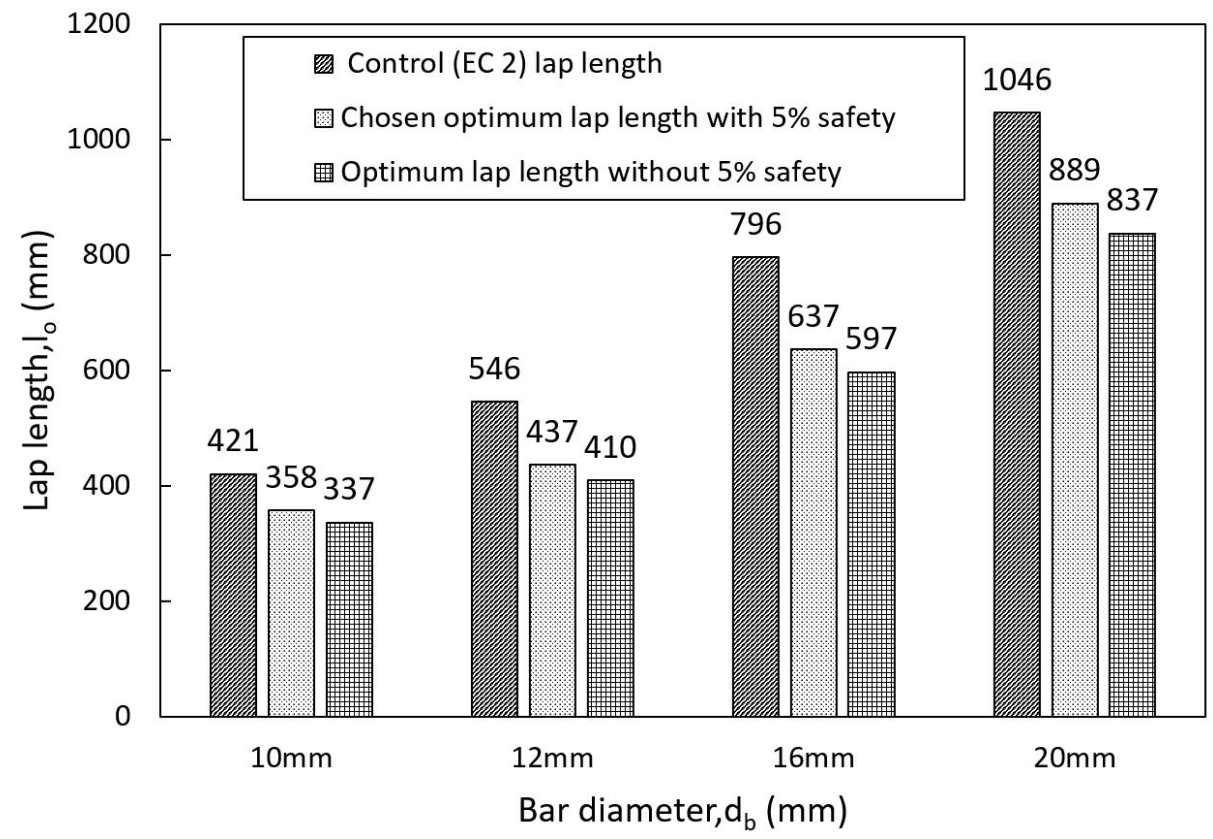

Figure 24: Optimised lap length $(\mathrm{mm})$

\subsection{Choice of optimum lap length $\left(I_{0}\right)$}

With regards to the obtained failure load in this research on the safety lap zones (see Figure 19, 20, 21 and 22), it indicates that the reinforced concrete beam will fail for any percentage reduction in lap length for steel reinforcement diameters $10 \mathrm{~mm}$ and $20 \mathrm{~mm}$ more than $20 \%$ resulting in an optimum lap length of $337 \mathrm{~mm}$ and $837 \mathrm{~mm}$ respectively. While failure will only occur in a reinforced concrete beam for any percentage lap length reduction more than $25 \%$ for $12 \mathrm{~mm}$ and $16 \mathrm{~mm}$ steel reinforcement bar diameters resulting in an optimum lap length of $410 \mathrm{~mm}$ and $597 \mathrm{~mm}$ respectively (see Table 5). However, a chosen optimum lap length with a $5 \%$ safety factor in comparison with the obtained optimum lap length without $5 \%$ safety factor and the control (EC 2) lap length was identified (see Figure 24). This introduced $5 \%$ reduction for the chosen optimum lap length is to serve as a design safety for the overall design as certain critical checks such as bond strength of the lapped section, bond slip failure etc. was not carried out during the FEA analysis by ANSYS due to its limitations on these identified checks.

\subsection{Validation of the analysed FEA reinforeced concrete models}

The flexural behaviour and progressive failure of the beam section shown in Figure 25(a) can be described using the Moment-Curvature graph in Figure 25(b). As the applied load increases, it increases the applied moment which induces curvature on the beam. As seen, four distinct stages are identified based on the elasto-plastic deformation of the singly reinforced composite beam. 


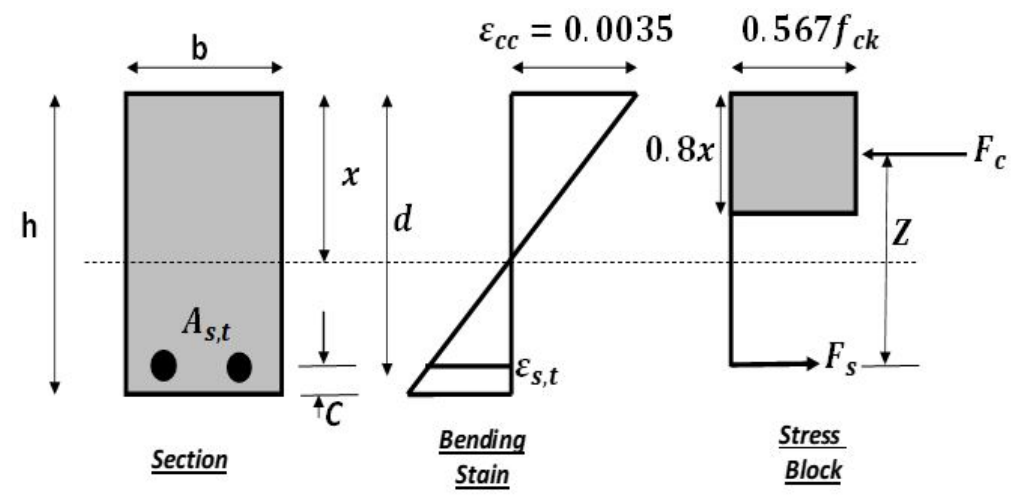

(a)

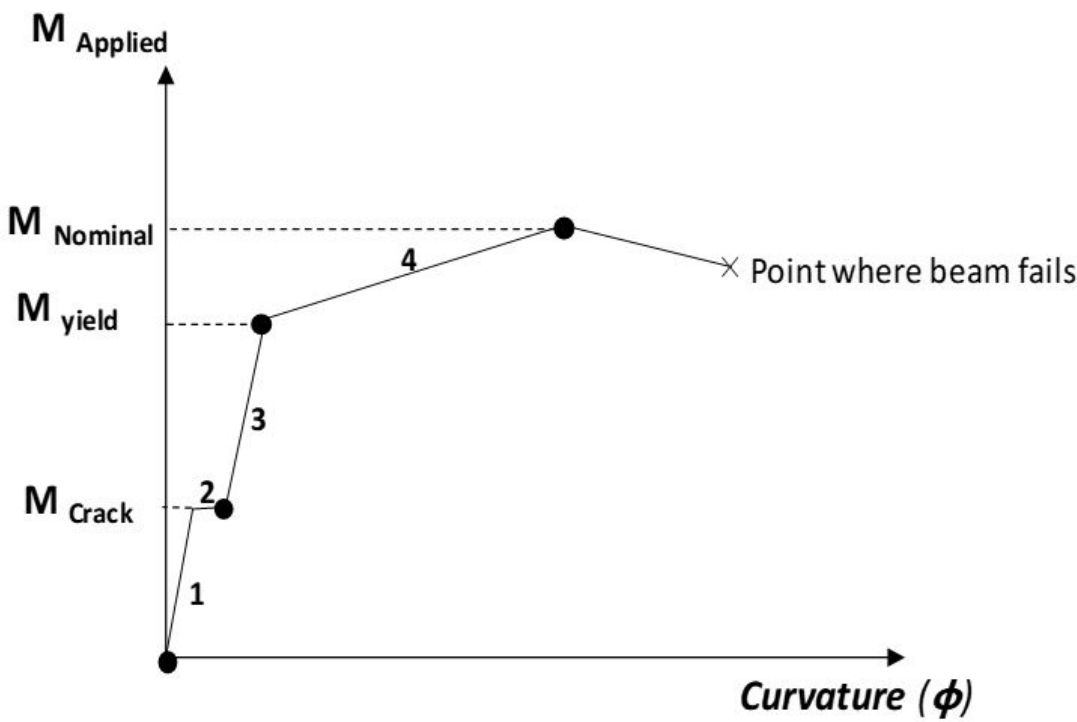

Stage 1: Concrete is un-cracked \& composite acts as L-E material

Stage 2: Concrete cracks in tension \& composite acts as L-E material

Stage 3: Concrete cracking propagates in tension \& compositeacts as L-E material (in-service behaviour)

Stage 4: Reinforcing Steels yielded, Ultimate moment reached \& Concrete crushes in compression

(b)

Figure 25: a) Beam cross section, bending strain distribution and Whitney rectangular stress block, (b) Moment-Curvature graph

For the un-cracked section, stage 1, the composite material behaves elastically and the strain definition is given by:

$$
\left.\begin{array}{c}
\varepsilon_{c, t}<\varepsilon_{\text {rupture }} \\
\varepsilon_{s, t}<\varepsilon_{y} \\
\varepsilon_{c, c}<\varepsilon_{P l, c}
\end{array}\right\}
$$

For stage 2, concrete cracks in tension as the applied moment $\left(\boldsymbol{M}_{\boldsymbol{A p p}}\right)$ attains the cracking moment $\left(\boldsymbol{M}_{\boldsymbol{c r}}\right)$, tensile steels and concrete in compression in zone are still within their proportionality limits and the strain definition is given by:

$$
\left.\begin{array}{c}
\varepsilon_{c, t}=\varepsilon_{\text {rupture }} \\
\varepsilon_{s, t}<\varepsilon_{y} \\
\varepsilon_{c, c}<\varepsilon_{P l, c}
\end{array}\right\}
$$

For stage 3, concrete in tension zone is assumed lost due to crack propagation, thus only tensile steels acts in composite with the concrete in compression zone to provide resistance against the applied moment, and the strain definition is given by: 


$$
\left.\begin{array}{c}
\varepsilon_{c, t}>\varepsilon_{\text {rupture }} \\
\varepsilon_{s, t}<\varepsilon_{y} \\
\varepsilon_{c, c}<\varepsilon_{P l, c}
\end{array}\right\}
$$

For stage $4, \varepsilon_{s, t} \gg \varepsilon_{y}$, the tensile reinforcing steels behave non-linearly, and Whitney rectangular stress distribution can be assumed, such that the nominal or ultimate moment:

$M n=F_{s, t} \cdot Z=F_{C} \cdot Z$

Where, $\varepsilon_{c, t}=$ strain in concrete in tension; $\varepsilon_{\text {rupture }}=$ strain in concrete at rupture; $\varepsilon_{s, t}=$ strain in steel in tension; $\varepsilon_{y}=$ yield strain of steel; $\varepsilon_{c, c}=$ strain in concrete in compression; $\varepsilon_{P l, c}=$ strain associated with proportional limit of concrete; $F_{s, t}=$ force in tensile steels; $F_{c}=$ force in concrete in compression zone and $Z=$ lever arm.

In this numerical investigation, beam was loaded to stage 3 of Figure 25(b) described above, hence analysis based on transformed area method was employed to verify the numerical results. The following analytical steps were implemented for each reinforcing diameter:

1. Determination of the neutral-axis from the top fibre of the beam using the expression:

$\frac{b x^{2}}{2}+\eta \cdot A_{s, t} \cdot x-\eta \cdot A_{s, t} \cdot d=0$

2. Determination of Area moment of inertia using the expression:

$I_{\text {Composite }}=\frac{b x^{3}}{12}+\frac{b x^{2}}{2}+\eta \cdot A_{s, t} \cdot(d-x)^{2}$

3. Determination of applied moment up till $\mathbf{M}_{\text {yield }}$ using the expression:

$M_{\text {yield }}=\frac{\sigma_{c, c} \cdot I_{\text {Composite }}}{x}$

Where, $x=$ depth of neutral-axis from the top fibre, $\mathrm{\eta}=$ modular ratio $=\frac{E_{\text {steel }}}{E_{\text {concrete }}} ; \sigma_{c, c}=$ Allowable stress in concrete in compression zone.

The results presented in Table 6 and Figure 26 show that the estimated theoretical moments are very similar to the moments obtained in the numerical studies both in magnitude and trend.

Table 6: Model validation results

\begin{tabular}{|c|c|c|c|c|}
\hline \multirow{2}{*}{ Parameters for analysis } & \multicolumn{4}{|c|}{ Manual calculation validation } \\
\hline & $10 \mathrm{~mm}$ bar & $12 \mathrm{~mm}$ bar & $16 \mathrm{~mm}$ bar & $20 \mathrm{~mm}$ bar \\
\hline Applied load at yield (kN) & 47.7 & 54.9 & 67.7 & 78.5 \\
\hline Ultimate moment of reistance ( $\mathrm{KNm})$ & 13.7 & 15.8 & 19.5 & 22.6 \\
\hline Depth of neutral axis, $x(\mathrm{~mm})$ & 51.7 & 60.4 & 76.5 & 90.9 \\
\hline $\begin{array}{l}\text { Maximum allowable compressive stress in } \\
\text { concrete, } f_{c}\left(\mathrm{~N} / \mathrm{mm}^{2}\right)\end{array}$ & 17.01 & 17.01 & 17.01 & 17.01 \\
\hline Elastic modulus of concrete, $E_{c}\left(\mathrm{~N} / \mathrm{mm}^{2}\right)$ & 27900 & 27900 & 27900 & 27900 \\
\hline Elastic modulus of steel, $E_{s}\left(\mathrm{~N} / \mathrm{mm}^{2}\right)$ & 205000 & 205000 & 205000 & 205000 \\
\hline Modular ratio, $\eta$ & 7.348 & 7.348 & 7.348 & 7.348 \\
\hline Transformed moment of inertia, $I_{t r}\left(\mathrm{~mm}^{4}\right)$ & 41565847.0 & 56061720.0 & 87575056.0 & 120612389.0 \\
\hline
\end{tabular}




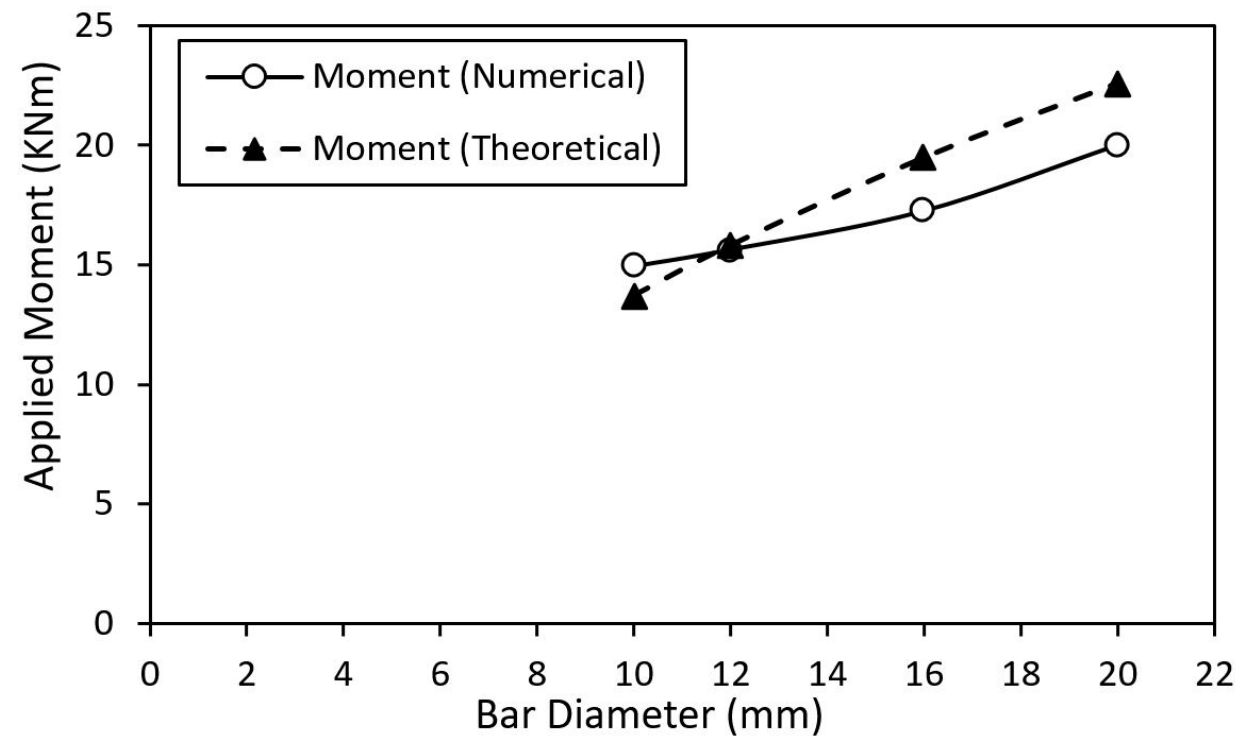

Figure 26: Numerical and theoretical moments for model validation

\subsection{CONCLUSION}

Specific conclusions that can be drawn from this research are as follows:

1. It is deduced that that the tension lap length $\left(\mathrm{I}_{0}\right)$ as required by EC2 for a reinforced concrete beam is conservative. Therfore, it posses a potential for the use of $15 \%$ and $20 \%$ reduction in the obtained lap length $\left(\mathrm{I}_{\mathrm{o}}\right)$ for tension steel reinforcement bar sizes of $10 \mathrm{~mm}, 16 \mathrm{~mm}$ and $12 \mathrm{~mm}, 20 \mathrm{~mm}$ respectively in comparison with the design lap length as evaluated using the requirements provided by EC2.

2. It's discovered that there is a gradual reduction in the failure load for every $5 \%$ reduction in lap lengths for all the reinforcement bar diameters. This observed trend of reduction in failure loads due to lap length reduction could be attributed to the reduction in the percentage amount of reinforcement required within the tension zone of a lapped tension reinforcement.

3. The relationship between reinforcement bar diameter $\left(d_{b}\right)$ and tension lap length $\left(l_{0}\right)$ shows that a linear relationship exists between the reinforcement bar diameter $\left(d_{b}\right)$ and the lap length. This means that for every increase in steel reinforcement bar sizes, there is a corresponding increase in the obtained tension lap length for a reinforced concrete beam.

4. The results also suggest that the steel reinforcement diameter sizes possess an effect on the overall tensile strength of a reinforced concrete beam. This is however opposed to compression lap lengths, where the steel diameter does not have a considerable influence on the compressive strength.

5. The investigation indicates that the reinforced concrete beam will fail for any percentage reduction in lap length for steel reinforcement diameters $10 \mathrm{~mm}$ and $20 \mathrm{~mm}$ more than $20 \%$ resulting in an optimum lap length of $337 \mathrm{~mm}$ and $837 \mathrm{~mm}$ respectively; while failure will only occur in a reinforced concrete beam for any percentage lap length reduction more than $25 \%$ for $12 \mathrm{~mm}$ and $16 \mathrm{~mm}$ steel reinforcement bar diameters resulting in an optimum lap length of $410 \mathrm{~mm}$ and $597 \mathrm{~mm}$ respectively.

6. The flexural capacities of a reinforced concrete beam can be predicted using numerical method based on FEA program.

7. The main factors which influences a design lap length in accordance with EC2 are as follows:

- $\quad$ Characteristics yield strength of steel, $f_{\mathrm{yk}}$

- Diameter of tension reinforcement bar, $d_{b}$

- Ultimate uniaxial tensile cracking strength of concrete, $\mathrm{f}_{\mathrm{ctd}}$

- Concrete cover, $c_{d}$ 
Author's Contributions: Conceptualization, BO Adeleke; Investigation, BO Adeleke; Methodology, BO Adeleke; Project administration, SJ Abbey; Resources, BO Adeleke and SJ Abbey; Software, BO Adeleke; Supervison, SJ Abbey and AO Olubanwo; Formal analysis, BO Adeleke, AO Olubanwo and SJ Abbey; Validation, BO Adeleke and AO Olubanwo; Visualization, SJ Abbey; Writing - original draft, BO Adeleke and SJ Abbey; Writing - review \& editing, BO Adeleke, SJ Abbey and AO Olubanwo; Resources, BO Adeleke and SJ Abbey.

Editor: Marcílio Alves.

\section{References}

Abdel-Kareem, A., Abousafa, H. and El-Hadidi, O. (2015). Behavior Of A Confined Tension Lap Splice In High-Strength Reinforced Concrete Beams. Slovak Journal of Civil Engineering, [online] 23(3), pp.1-8. Available at: https://www.degruyter.com/downloadpdf/j/sjce.2015.23.issue-3/sjce-2015-0011/sjce-2015-0011.pdf

Adams, Vince and Askenazi, Abraham. (1999) Building Better Products with Finite Element Analysis. USA: On Word Press.

Al-Ta'an, P., Mohammed, A. and Al-Jurmaa, M. (2010). NONLINEAR THREE DIMENSIONAL FINITE ELEMENT ANALYSIS OF STEEL FIBER REINFORCED CONCRETE DEEP BEAM. The Iraqi Journal For Mechanical And Material Engineering, [online] (1819-2076), pp.13-35. Available at:

https://www.researchgate.net/publication/263047409_Nonlinear_Three_Dimensional_Finite_Element_Analysis_of_Steel_Fib er_Reinforced_Concrete_Deep_Beam

ANSYS Inc, 2014. ANSYS Mechanical Theory Reference: Release 15.0. Canonsburg PA, USA.

Balazs, G., Cairns, J., Eligehausen, R., Lettow, S., Metelli, G., Pantazopoulou, S. and Plizzari, G. (2014). Bond and anchorage of embedded reinforcement: background to the fib model code for concrete structures 2010. 1st ed. Lausanne: FIB.

Barbato, M. (2009). Efficient finite element modelling of reinforced concrete beams retrofitted with fibre reinforced polymers. Computers \& Structures, [online] 87(3-4), pp.167-176. Available at: http://www.sciencedirect.com/science/article/pii/S0045794908002502

Boye B. A., Abbey S. J, Olubanwo A. O., Fonte J. (2018). Non-Linear Analysis of Precast Concrete Segment Joints under High Compressive Loads International Journal of Applied Engineering Research 13 (9), 6979-6988

Boye, B., Abbey, S., Ngambi, S. and Fonte, J. (2019). Development of Improved Models for Estimation of Bursting Stresses in Elements under High-Concentrated Load. Latin American Journal of Solids and Structures, 16(1), pp. 1-15

BS EN 1992-1-1:2004+A1:2014 - Eurocode 2: Design of concrete structures. General rules and rules for buildings

Cairns, J. (2016). An evaluation of EC2 rules for design of compression lap joints. Structures, 5, pp.35-43. [online] Available at: http://www.sciencedirect.com/science/article/pii/S2352012415000673

Cashman, J. and Gopal, A. (2014). ANSYS Workbench. USA: ANSYS, Inc.

Draycott, T. and Bullman, P. (2009) Structural elements design manual: Working with Eurocodes. 2nd edn. Amsterdam: Butterworth-Heinemann.

El-Azab, A. and Mohamed, H. (2014). Effect of tension lap splice on the behaviour of high strength concrete (HSC) beams. HBRC Journal, [online] 10(3), pp.287-297. Available at: http://www.sciencedirect.com/science/article/pii/\$1687404814000066

Hu, H., Lin, F. and Jan, Y. (2004). Nonlinear finite element analysis of reinforced concrete beams strengthened by fiberreinforced plastics. Composite Structures, 63(3-4), pp.271-281.

Islam, M., Khatun, M., Islam, M., Dola, J., Hussan, M. and Siddique, A. (2014). Finite Element Analysis of Steel Fiber Reinforced Concrete (SFRC): Validation of Experimental Shear Capacities of Beams. Procedia Engineering, 90, pp.89-95.

J. Cairns, R. Eligehausen (2014) Evaluation of EC2 rules for design of tension lap joints Structl Eng, 92 (No. 9)

Lagier, F., Massicotte, B. and Charron, J. (2015). Bond strength of tension lap splice specimens in UHPFRC. Construction and Building Materials, [online] 93, pp.84-94. Available at: http://www.sciencedirect.com/science/article/pii/S0950061815005061

Lawrence, K. (2006). ANSYS workbench tutorial. 1st ed. [S.I.]: SDC. 
Mousa, M. (2015). Flexural behaviour and ductility of high strength concrete (HSC) beams with tension lap splice. Alexandria Engineering Journal, [online] 54(3), pp.551-563. Available at: http://www.sciencedirect.com/science/article/pii/S1110016815000496

Olubanwo A. O., Karadelis J. N., Abbey S. J. (2017). Evaluation of Equivalent Delamination Driving Coefficient in Bonded Concrete Overlays. International Journal of Civil Engineering \& Technology (IJCIET) 8 (5), pp. 1436-1444.

Olubanwo A. O., Karadelis J. N., Saidani M., Khorami M., Abbey S. J. (2018). Investigation of intrinsic de-bonding in bonded concrete overlays: Material characterisation and numerical Study Engineering Solid Mechanics 6 (2), 155-174

Srinivasan, R. and Sathiya, K. (2010). Flexural Behavior of Reinforced Concrete Beams Using Finite Element Analysis (Elastic. CONSTRUCTII. ĂRHITECTURĂ. [online] Available at: http://www.bipcons.ce.tuiasi.ro/Archive/199.pdf

Si, B., Sun, Z., Ai, Q., Wang, D. and Wang, Q. (2008). EXPERIMENTS AND SIMULATION OF FLEXURAL-SHEAR DOMINATED RC BRIDGE PIERS UNDER REVERSED CYCLIC LOADING. The 14th World Conference on Earthquake Engineering. [online] Available at: http://www.iitk.ac.in/nicee/wcee/article/14_12-03-0027.PDF.

Zhang, X., Chen, Z. and Liu, Y. (2017). The Material Point Method. The Material Point Method, [online] pp.37-101. Available at: https://www.sciencedirect.com/science/article/pii/B978012407716400003X. 